\title{
Exit and Power in General Equilibrium
}

\author{
HANS GERSBACH \\ HANS HALLER
}

\author{
CESIFO WORKING PAPER NO. 2369 \\ CATEGORY 10: EMPIRICAL AND THEORETICAL METHODS \\ August 2008
}
An electronic version of the paper may be downloaded
- from the SSRN website: Www.SSRN.com
- from the RePEc website: $\quad$ www.RePEc.org
- from the CESifo website: www.CESifo-group.org/wp




\title{
Exit and Power in General Equilibrium
}

\begin{abstract}
We integrate individual power in groups into general equilibrium models. The relationship between group formation, resource allocation, and the power of specific individuals or particular sociological groups is investigated. We introduce, via an illustrative example, three appealing concepts of power and show that there is no monotonic relationship between these concepts. Then we examine existence of competitive equilibria with free exit and study whether maximal individual power is consistent with Pareto efficiency. As applications, we discuss when power spillovers occur and we identify human relation paradoxes: positive externalities increase, but none of the household members gains in equilibrium. We further identify implicit, determinate and de facto power.
\end{abstract}

JEL Code: D41, D50, D60.

Keywords: group formation, competitive markets, power, exit.

Hans Gersbach

CER-ETH-Center of Economic Research at ETH Zurich

Zürichbergstrasse 18

8092 Zurich

Switzerland

hgersbach@ethz.ch

\author{
Hans Haller \\ Department of Economics \\ Virginia Polytechnic Institute and State \\ University \\ Blacksburg, VA 24061-0316 \\ USA \\ haller@vt.edu
}

This version: July 2008

We thank Clive Bell, Theresa Fahrenberger, Martin Hellwig, Benny Moldovanu, Martin Scheffel, and seminar participants in Basel, Berlin and Heidelberg for helpful comments. 


\section{Introduction}

Two of the characteristic traits of contemporary advanced societies are enhanced influence (more bargaining power) of women and the large increase of single-person households. An intriguing question is therefore how the general equilibrium allocation of resources and the formation of households are related to the power of particular sociological groups.

In this paper we examine how individual power in groups can be integrated into general equilibrium model and which type of phenomena we can explain by our model. We discuss power under the assumption that individuals have the possibility to exit (leave a multi-member household) and to form a single-person household or, in addition, to join other households. Household members have individual preferences. The members of a household make efficient collective consumption decisions where different households may use different collective decision mechanisms. Households operate within a competitive market environment. Moreover, at the going prices, individuals may decide to become singles or to join other households. Therefore, neither households nor deserting members have any market power. Nonetheless, individuals can exert power in multi-member households. The departure from the traditional model of pure exchange enables us to examine individual power in such households. Moreover, we are able to identify and analyze the household structures that can prevail in equilibrium.

We introduce via example three different concepts of power when group or consumption externalities are present: "utilitarian power" as the weight of an individual in the household welfare function, "bargaining power" as the weight of an individual in the Nash-bargained decision of a household and "real power" as the incremental utility an individual can achieve in a household in comparison with other possibilities, in particular in comparison with exit.

Absence of externalities implies absence of bargaining or real power. In a two-person household, a person creates externalities if, and only if, the other person receives externalities, and vice versa. Therefore, if a member neither creates nor receives externalities, then both members lack bargaining or real power. We show that as soon as the group size exceeds two, certain individuals can have bargaining and real power even if they do not create or receive externalities themselves. We also show that there is no monotonic relationship between the three power concepts. 
In the next step we study how real power is related to the efficiency of allocations. After establishing existence of equilibria with free exit, we identify several cases where Pareto-efficiency and manifestation of power go hand in hand.

We further study the special case of quasi-linear preferences to illustrate the main results. We also use this case to illustrate what is called power spillovers: Changes in bargaining or utilitarian power in particular households impact on other households.

Finally, we present various applications of our concepts. In particular, we exhibit human relations paradoxa where none of the household members gains in equilibrium, although non-consumptive benefits from household formation increase. Moreover, we demonstrate how implicit and determinate power and de jure and de facto power can be derived from our power concepts.

The notion of power can have very different meanings in economics. Concepts such as market power, veto power, agenda setting power, voting power, bargaining power, and power indices are well known. ${ }^{1}$ In this paper, we offer a framework to define power in a general equilibrium framework. Our paper is in the tradition of cooperative models of households as recently surveyed by Apps and Rees (2007). We integrate collective rationality of households into a general equilibrium model and we examine the role of individual power in such a framework. Our paper is also related to the influential work of Hirschman (1970) who has considered the comparative efficiency of the exit and voice options as mechanisms of recuperation. One of our main results suggests that the outside options limit power as long as externalities in groups are sufficiently small.

The paper is organized as follows. In the next two sections, we introduce the formal framework and define an equilibrium with free exit and free household formation. In section 4, we study different concepts of power in groups and discuss their relationship and equilibrium implications. In section 5, we discuss the relationship between power and Pareto efficiency. In section 6, we consider the special case of quasi-linear utilities. Section 7 contains applications. Section 8 concludes.

\footnotetext{
${ }^{1}$ Bell (1991) provides a subtle discussion of different concepts of power in the literature on economic development.
} 


\section{Consumer Characteristics and Allocations}

In this section, we describe the basic structure of the model: consumers, household structures, commodities, endowments, allocations, and preferences.

Consumers and Household Structures. We consider a finite population of consumers, represented by a set $I=\{1, \ldots, n\}$. A generic consumer is denoted by $i$ or $j$. The population $I$ is partitioned into households, i.e. there exists a partition $P$ of $I$ into non-empty subsets. We call any such partition $P$ a household structure in $I$. If $P$ consists of $H$ households, we frequently label them $h=1, \ldots, H$, provided this causes no confusion. We treat the household structure as an object of endogenous choice. Households are endogenously formed so that some household structure $P$ is ultimately realized. Consequently, our consumer allocation space is $\mathcal{P}$, the set of all household structures in $I$. A generic household is denoted by $h$ or $g$. A single person household formed by individual $i$ is denoted by $\{i\}$. We denote $\mathcal{H}=\{h \subseteq I: h \neq \emptyset\}$, the set of all potential households.

Commodities. There exists a finite number $\ell \geq 1$ of commodities. Each commodity is formally treated as a private good, possibly with externalities in consumption. Each consumer $i \in I$ has a consumption set $X_{i}=\mathbb{R}_{+}^{\ell}$ so that the commodity allocation space is $\mathcal{X} \equiv \prod_{j \in I} X_{j}$. Generic elements of $\mathcal{X}$ are denoted $\mathbf{x}=\left(x_{i}\right)_{i \in I}, \mathbf{y}=\left(y_{i}\right)_{i \in I}$. Commodities are denoted by superscripts $k=1, \ldots, \ell$. For a potential household $h \in \mathcal{H}$, set $\mathcal{X}_{h}=\prod_{i \in h} X_{i}$, the consumption set for household $h . \mathcal{X}_{h}$ has generic elements $\mathbf{x}_{\mathbf{h}}=\left(x_{i}\right)_{i \in h}$. If $\mathbf{x}=\left(x_{i}\right)_{i \in I} \in \mathcal{X}$ is a commodity allocation, then consumption for household $h$ is $\mathbf{x}_{\mathbf{h}}=\left(x_{i}\right)_{i \in h}$, the restriction of $\mathbf{x}=\left(x_{i}\right)_{i \in I}$ to $h$.

Endowments. For a potential household $h \in \mathcal{H}$, its endowment is a commodity bundle $\omega_{h} \in \mathbb{R}^{\ell}$ given by the sum of the endowments of all participating individuals: $\omega_{h}=\sum_{i \in h} \omega_{\{i\}}$. The social endowment is given by

$$
\omega_{S} \equiv \sum_{h \in P} \omega_{h}=\sum_{i \in I} \omega_{\{i\}}
$$

Allocations. An allocation is a pair $(\mathbf{x} ; P) \in \mathcal{X} \times \mathcal{P}$ specifying the consumption bundle and household membership of each consumer. We call an allocation $(\mathbf{x} ; P) \in$ 
$\mathcal{X} \times \mathcal{P}$ feasible, if

$$
\sum_{i \in I} x_{i} \leq \omega_{S}
$$

After the specification of individual preferences, by means of utility representations, an allocation determines the welfare of each and every member of society.

Consumer Preferences. In principle, a consumer might have preferences on the allocation space $\mathcal{X} \times \mathcal{P}$ and care about each and every detail of an allocation. For individual $i \in I$, we assume that $i$ has preferences on $\mathcal{X} \times \mathcal{P}$ represented by a utility function $U_{i}: \mathcal{X} \times \mathcal{P} \longrightarrow \mathbb{R}$.

In the following, we shall make the general assumption that an individual does not care about the features of an allocation beyond the boundaries of his own household. If a particular household structure is given, he is indifferent about the affiliation and consumption of individuals not belonging to his own household. Condition HSP is a formal expression of this assumption — with a slight abuse of notation.

(HSP) Household-Specific Preferences:

$$
U_{i}(\mathbf{x} ; P)=U_{i}\left(\mathbf{x}_{\mathbf{h}} ; h\right) \text { for } i \in h, h \in P,(\mathbf{x} ; P) \in \mathcal{X} \times \mathcal{P} .
$$

The general assumption HSP is justifiable on the grounds that we want to design a model where multi-member households play a significant allocative role. HSP still admits a lot of flexibility. For example, it permits various types of consumption externalities. Later on, we shall exploit the occurrence of pure group externalities that depend solely on the persons belonging to a household. To formulate the latter kind of externalities, define $\mathcal{H}_{i} \equiv\{h \subseteq I \mid i \in h\}$ for $i \in I$. $\mathcal{H}_{i}$ is the set of potential households of which $i$ would be a member.

\section{(PGE) Pure Group Externalities:}

For each consumer $i$, there exist functions $U_{i}^{c}: X_{i} \rightarrow \mathbb{R}$ and $U_{i}^{g}: \mathcal{H}_{i} \rightarrow \mathbb{R}$ such that $U_{i}\left(\mathbf{x}_{\mathbf{h}} ; h\right)=U_{i}^{c}\left(x_{i}\right)+U_{i}^{g}(h)$ for $\mathbf{x}_{\mathbf{h}} \in \mathcal{X}_{h}, h \in \mathcal{H}_{i}$.

PGE assumes that one can additively separate the pure consumption effect $U_{i}^{c}\left(x_{i}\right)$ from the pure group effect $U_{i}^{g}(h)$. Separation with respect to the consumption of individual household members may also be possible. A very special case is the absence 
of externalities, corresponding to $U_{i}^{g} \equiv 0$. Since we will refer to it repeatedly, let us distinguish this case by its own acronym.

\section{(ABS) Absence of Externalities:}

$$
U_{i}(\mathbf{x} ; P)=U_{i}\left(x_{i}\right) \text { for } i \in I,(\mathbf{x} ; P) \in \mathcal{X} \times \mathcal{P} .
$$

Optimality. We say that an allocation $(\mathbf{x} ; P)$ is fully Pareto optimal if $(\mathbf{x} ; P)$ is feasible and there is no feasible allocation $\left(\mathbf{x}^{\prime} ; P^{\prime}\right)$ that satisfies $\left(U_{i}\left(\mathbf{x}^{\prime} ; P^{\prime}\right)\right)_{i \in I}>$ $\left(U_{i}(\mathbf{x} ; P)\right)_{i \in I}{ }^{2}$ Denote by $\mathcal{M}^{*}$ the set of fully Pareto optimal allocations. If all utility functions are continuous in consumption, $\mathcal{M}^{*}$ is not empty (Gersbach and Haller (2001)). We denote by $\mathcal{P}^{*} \subseteq \mathcal{P}$ the set of all potentially optimal household structures, i.e. $P \in \mathcal{P}^{*}$ if, and only if, there exists $\mathbf{x}$ such that $(\mathbf{x} ; P) \in \mathcal{M}^{*}$.

\section{Equilibrium}

There are several conceivable ways to formulate an equilibrium state of a model with variable household structure. We follow Gersbach and Haller (2003) and employ the concepts of a competitive equilibrium with free exit, and of a competitive equilibrium with free household formation. We introduce the formal definitions of both equilibrium concepts. We consider a household $h \in P$ and a price system $p \in \mathbb{R}_{+}^{\ell}$. For $\mathbf{x}_{\mathbf{h}}=$ $\left(x_{i}\right)_{i \in h} \in \mathcal{X}_{h}$

$$
p * \mathbf{x}_{\mathbf{h}} \equiv p \cdot\left(\sum_{i \in h} x_{i}\right)
$$

denotes the expenditure of household $h$ on household consumption plan $\mathbf{x}_{\mathbf{h}}$ at the price system $p$. As $p$ and $\mathbf{x}_{\mathbf{h}}$ are of different dimension for multi-member households, we use the $*$-product in lieu of the familiar inner product. Then $h$ 's budget set is defined as

$$
B_{h}(p)=\left\{\mathbf{x}_{\mathbf{h}} \in \mathcal{X}_{h}: p * \mathbf{x}_{\mathbf{h}} \leq p \cdot \omega_{h}\right\}
$$

We next define the efficient budget set $E B_{h}(p)$ as the set of $\mathbf{x}_{\mathbf{h}} \in B_{h}(p)$ with the property that there is no $\mathbf{y}_{\mathbf{h}} \in B_{h}(p)$ such that

(i) $U_{i}\left(\mathbf{y}_{\mathbf{h}} ; h\right) \geq U_{i}\left(\mathbf{x}_{\mathbf{h}} ; h\right)$ for all $i \in h$;

\footnotetext{
${ }^{2}$ The notation " $>$ " means in this context that $U_{i}\left(\mathbf{x}^{\prime} ; P^{\prime}\right) \geq U_{i}(\mathbf{x} ; P)$ for all $i \in I$ and $U_{i}\left(\mathbf{x}^{\prime} ; P^{\prime}\right)>$ $U_{i}(\mathbf{x} ; P)$ for at least one $i \in I$.
} 
(ii) $U_{i}\left(\mathbf{y}_{\mathbf{h}} ; h\right)>U_{i}\left(\mathbf{x}_{\mathbf{h}} ; h\right)$ for some $i \in h$.

Further we define a state of the economy as a triple $(p, \mathbf{x} ; P)$ such that $p \in \mathbb{R}_{+}^{\ell}$ is a price system and $(\mathbf{x} ; P) \in \mathcal{X} \times P$ is an allocation, i.e. $\mathbf{x}=\left(x_{i}\right)_{i \in I}$ is an allocation of commodities and $P$ is an allocation of consumers (a household structure, a partition of the population into households). A state $(p, \mathbf{x} ; P)$ is a competitive equilibrium with free exit (CEFE) if it satisfies the following conditions:

1. $\mathbf{x}_{\mathbf{h}} \in E B_{h}(p)$ for all $h \in P$.

2. $\sum_{i \in I} x_{i}=\omega_{S}$.

3. There are no $h \in P, i \in h$ and $y_{i} \in B_{\{i\}}(p)$ such that $U_{i}\left(y_{i} ;\{i\}\right)>U_{i}\left(\mathbf{x}_{\mathbf{h}} ; h\right)$.

Finally a competitive equilibrium with free household formation (CEFH) is a $\operatorname{CEFE}(p, \mathbf{x} ; P)$ that also satisfies:

4. There are no $h \in P$ and $g \in P, i \in h$ and $\mathbf{y}_{\mathbf{g} \cup\{\mathbf{i}\}} \in B_{g \cup\{i\}}(p)$ such that

$$
\begin{aligned}
& U_{j}\left(\mathbf{y}_{\mathbf{g} \cup\{\mathbf{i}\}} ; g \cup\{i\}\right)>U_{j}\left(\mathbf{x}_{\mathbf{g}} ; g\right) \text { for all } j \in g ; \\
& U_{i}\left(\mathbf{y}_{\mathbf{g} \cup\{\mathbf{i}\}} ; g \cup\{i\}\right)>U_{i}\left(\mathbf{x}_{\mathbf{h}} ; h\right) .
\end{aligned}
$$

Condition 1 reflects collective rationality as developed in the seminal contributions by Chiappori (1988a, 1992) and Apps and Rees (1997), in contrast to the traditional "unitary" model where households are treated like single consumers. Efficient choice by the household refers to the individual consumption and welfare of its members, not merely to the aggregate consumption bundle of the household. Condition 2 requires market clearing. Conditions 1 and 2 alone define a competitive equilibrium $(p, \mathbf{x})$, given household structure $P$, discussed and studied in Haller (2000) and Gersbach and Haller (2001).

In addition, we impose condition 3 that no individual wants to leave a household and participate as a one-member household in the market at the going equilibrium prices. Condition 3 constitutes an individual rationality or voluntary participation (membership) constraint. Conditions 1 to 3 together define a competitive equilibrium with free exit. Conditions 1 to 4 together define a competitive equilibrium with free household formation. Condition 4 requires that no individual can leave a household 
and can propose a feasible consumption allocation to the members of a new household, created by the individual and another already existing household, which makes everybody in the new household better off at the going equilibrium prices. We will work primarily with CEFE. However, our concepts are applicable to CEFH, and some of our examples allow for the more demanding equilibrium concept.

\section{Example 1: The Notion of Power}

Any discussion and definition of power in the present context ought to begin with the neutrality theorem of Gersbach and Haller (2003). The neutrality or no-power theorem states that in the absence of any externalities, individuals cannot achieve higher utility levels by participating in households rather than acting and trading individually - which renders the notion of power within households obsolete. For power to exist, there has to be some advantage, some positive externality in household formation. ${ }^{3}$ We are going to show that the existence of externalities can, indeed, create power for agents in a group. This is illustrated in an example with positive group externalities. The example also serves to introduce three concepts of power.

\subsection{Primitive Data of Example 1}

Let $\ell=2, I=\{1,2,3\}$. Preferences are represented by $U_{i}\left(\mathbf{x}_{\mathbf{h}} ; h\right)=U_{i}\left(x_{i}\right)+U_{i}^{g}(h)=$ $U_{i}\left(x_{i}^{1}, x_{i}^{2}\right)+U_{i}^{g}(h)$ where $x_{i}^{k}$ denotes the quantity of good $k(k=1,2)$ consumed by individual $i . U_{i}^{g}(h)$ captures the pure group externality contributing to the utility of individual $i$. Specifically, we assume

$$
\begin{aligned}
& U_{1}\left(x_{1}^{1}, x_{1}^{2}\right)+U_{1}^{g}(h)= \begin{cases}\ln x_{1}^{1}+\ln v_{1} & \text { in case } h=\{1,2\}, \text { with } v_{1} \geq 1 ; \\
\ln x_{1}^{1} & \text { in all other cases; }\end{cases} \\
& U_{2}\left(x_{2}^{1}, x_{2}^{2}\right)+U_{2}^{g}(h)= \begin{cases}\ln x_{2}^{2}+\ln v_{2} & \text { in case } h=\{1,2\}, \text { with } v_{2} \geq 1 ; \\
\ln x_{2}^{2} & \text { in all other cases; }\end{cases} \\
& U_{3}\left(x_{3}^{1}, x_{3}^{2}\right)+U_{3}^{g}(h)=\frac{1}{2} \ln x_{3}^{1}+\frac{1}{2} \ln x_{3}^{2} .
\end{aligned}
$$

\footnotetext{
${ }^{3}$ Another advantage of household formation could be household production. For instance, in a reduced form of household production, household formation could simply augment the initial endowment with resources: The collective endowment of a multi-member household could exceed the sum of the individual endowments of household members.
} 
The variables $v_{1}$ and $v_{2}$ stand for the extent of group externalities that individual 1 and 2 experience when they live together. We further assume the individual endowments

$$
w_{1}=(0,1 / 2), w_{2}=(0,1 / 2), w_{3}=(1,0) .
$$

\subsection{Equilibria}

Commodity prices are normalized so that $p_{1}=1$. We first look at equilibria with a fixed household structure. There exists a unique competitive equilibrium $\left(p^{0} ; \mathbf{x}^{\mathbf{0}} ; P^{0}\right)$, given the household structure $P^{0}=\{\{1\},\{2\},\{3\}\}$ :

$$
p^{0}=(1,1), x_{1}^{0}=(1 / 2,0), x_{2}^{0}=(0,1 / 2), x_{3}^{0}=(1 / 2,1 / 2) .
$$

We next calculate competitive equilibria with free exit for the household structure $P^{*}=\{\{1,2\},\{3\}\}$ where we assume that household $g=\{1,2\}$ maximizes a utilitarian social welfare function

$$
\begin{aligned}
W_{g} & =\alpha U_{1}\left(x_{1}\right)+(1-\alpha) U_{2}\left(x_{2}\right) \\
& =\alpha \ln x_{1}^{1}+(1-\alpha) \ln x_{2}^{2}+\alpha \ln v_{1}+(1-\alpha) \ln v_{2}
\end{aligned}
$$

subject to the budget constraint $x_{1}^{1}+p_{2} x_{2}^{2}=p_{2}$, where $0<\alpha<1$. The parameter $\alpha$ can be interpreted as the weight of individual 1 in household $g$. Similarly, $1-\alpha$ is the weight of individual 2 .

Since the group externalities do not affect excess demand vectors of household $g=$ $\{1,2\}$, the excess demand vectors of the households $g$ and $h=\{3\}$, denoted by $z_{g}$ and $z_{h}$, are given by

$$
\begin{aligned}
z_{g} & =\left(\alpha p_{2},-\alpha\right) \\
z_{h} & =\left(-\frac{1}{2}, \frac{1}{2 p_{2}}\right) .
\end{aligned}
$$

A market equilibrium without exit considerations $\left(p^{*}, \mathbf{x}^{*} ; P^{*}\right)$ would require

$$
p^{*}=(1,1 /(2 \alpha)), x_{1}^{*}=(1 / 2,0), x_{2}^{*}=(0,1-\alpha), x_{3}^{*}=(1 / 2, \alpha) .
$$




\subsection{Exit Conditions and Power}

The non-exit conditions in household $g$ amount to:

$$
\begin{aligned}
& U_{1}\left(x_{1}^{*}\right)=\ln \frac{1}{2}+\ln v_{1} \geq \ln \frac{1}{4 \alpha} \\
& U_{2}\left(x_{2}^{*}\right)=\ln (1-\alpha)+\ln v_{2} \geq \ln \frac{1}{2},
\end{aligned}
$$

which imply $\alpha \geq \frac{1}{2 v_{1}}=\underline{\alpha}$ and $\alpha \leq 1-\frac{1}{2 v_{2}}=\bar{\alpha}$. Hence, if $\alpha \in[\underline{\alpha}, \bar{\alpha}]=\left[\frac{1}{2 v_{1}}, 1-\frac{1}{2 v_{2}}\right]$, then $\left(p^{*}, \mathbf{x}^{*}, P^{*}\right)$ is a competitive equilibrium with free exit. We further obtain

Fact $1 \partial \underline{\alpha} / \partial v_{1}<0$ and $\partial \bar{\alpha} / \partial v_{2}>0$.

An increase in the positive externality of individual 1 decreases the lower bound on his weight in the household welfare function, since he is prepared to sacrifice more consumption in order to stay in the household. If $v_{1}=1$ we obtain $\underline{\alpha}=\frac{1}{2}$ and thus individual 1 has at least the same weight as individual 2. The opposite effects occur for $\bar{\alpha}$ when $v_{2}$ increases. $1-\bar{\alpha}$ and thus the lower bound of the weight of individual 2 declines. For $v_{2}=1$ we have $\bar{\alpha}=\frac{1}{2}$.

At this stage it is useful to distinguish between different notions of power in a group. We follow closely the setup of the example and assume that the two-person household $g$ maximizes a utilitarian welfare function. Then we can distinguish between three different concepts of power in a competitive equilibrium with free exit.

- Utilitarian power, the weight of an individual's utility in the household welfare function.

- Bargaining power, the weight of an individual in the Nash-bargaining decision of a household.

- Real power, the additional utility an individual can achieve in a household in comparison with exit.

To discuss the three notions of power we denote by $\beta$ and $1-\beta$ the relative bargaining power of individual 1 and 2 , respectively. Furthermore, let for $i=1,2, x_{i}^{0}\left(p_{2}\right)$ denote consumer $i$ 's individual demand at the price system $\left(1, p_{2}\right)$. 
Let us consider the possibility that, given the relative bargaining power, for every price $p_{2}$, household $g$ maximizes the Nash product

$$
\begin{aligned}
N_{g} & =\left\{U_{1}\left(x_{1}\right)-U_{1}\left(x_{1}^{0}\left(p_{2}\right)\right)\right\}^{\beta} \cdot\left\{U_{2}\left(x_{2}\right)-U_{2}\left(x_{2}^{0}\left(p_{2}\right)\right)\right\}^{1-\beta} \\
& =\left\{\ln \left(x_{1}^{1} \cdot v_{1}\right)-\ln \left(\frac{1}{2} p_{2}\right)\right\}^{\beta} \cdot\left\{\ln \left(x_{2}^{2} \cdot v_{2}\right)-\ln \frac{1}{2}\right\}^{1-\beta} .
\end{aligned}
$$

Note that the household $g=\{1,2\}$ uses as conflict outcomes the outside options available at the price $p_{2}$. The outside option values amount to $\ln \left(\frac{1}{2} p_{2}\right)$ for individual 1 , and $\ln \left(\frac{1}{2}\right)$ for the second individual. Using the household budget constraint $x_{1}^{1}=p_{2}-p_{2} x_{2}^{2}$, the first-order condition for maximizing $N_{g}$ amounts to:

$$
\beta \cdot \frac{x_{2}^{2}}{1-x_{2}^{2}}=(1-\beta) \cdot \frac{\ln \left(\left(1-x_{2}^{2}\right) \cdot 2 v_{1}\right)}{\ln \left(x_{2}^{2} \cdot 2 v_{2}\right)}
$$

This is an implicit equation for $x_{2}^{2}$. Now suppose the same allocation is obtained in a competitive equilibrium with free exit where the household maximizes its utilitarian welfare function, with respective weights $\alpha$ and $1-\alpha$. Then we have $x_{2}^{2}=1-\alpha$ and thus equation (4) is an implicit equation for $\beta(\alpha)$, the bargaining power of individual 1 that yields the same household decision as the household's utilitarian welfare maximum:

$$
\frac{\beta}{1-\beta}=\frac{\alpha}{1-\alpha} \frac{\ln \left(\alpha 2 v_{1}\right)}{\ln \left((1-\alpha) 2 v_{2}\right)}
$$

Note that by definition of $\beta(\alpha), \alpha$ in $W_{g}$ and $\beta=\beta(\alpha)$ in $N_{g}$ lead to the same allocation for household $g$. We obtain the following properties for $\beta(\alpha)$ :

Fact $2 \beta\left(\frac{1}{2 v_{1}}\right)=0, \beta\left(1-\frac{1}{2 v_{2}}\right)=1, \frac{\partial \beta}{\partial \alpha}>0$.

Higher utilitarian power, that is, a higher weight in the household welfare function, translates into higher relative bargaining power, as long as $\alpha$ is in the range $\left[\frac{1}{2 v_{1}}, 1-\frac{1}{2 v_{2}}\right]$ for which the competitive equilibrium with free exit involving household $g$ exists. The maximal utilities of the individuals are given by

$$
\begin{aligned}
& U_{1}= \begin{cases}\ln \frac{1}{2}+\ln v_{1} & \text { if } \alpha \in\left[\frac{1}{2 v_{1}}, 1-\frac{1}{2 v_{2}}\right] \\
\ln \frac{1}{2} & \text { if } \alpha \notin\left[\frac{1}{2 v_{1}}, 1-\frac{1}{2 v_{2}}\right]\end{cases} \\
& U_{2}= \begin{cases}\ln (1-\alpha)+\ln v_{2} & \text { if } \alpha \in\left[\frac{1}{2 v_{1}}, 1-\frac{1}{2 v_{2}}\right] \\
\ln \frac{1}{2} & \text { if } \alpha \notin\left[\frac{1}{2 v_{1}}, 1-\frac{1}{2 v_{2}}\right]\end{cases}
\end{aligned}
$$


where we have assumed that $\left(p^{*} ; \mathbf{x}^{*} ; P^{*}\right)$ prevails for $\alpha \in\left[\frac{1}{2 v_{1}}, 1-\frac{1}{2 v_{2}}\right]$ while only $\left(p^{0} ; \mathbf{x}^{\mathbf{0}} ; P^{0}\right)$ can occur for $\alpha \notin\left[\frac{1}{2 v_{1}}, 1-\frac{1}{2 v_{2}}\right]$.

We obtain the following comparisons of utilitarian, bargaining and real power.

- If $\alpha<\frac{1}{2 v_{1}}$ and thus agent 2 has a large weight $1-\alpha$, formation of household $g$ is impossible in equilibrium, since individual 1 would exit and utility is unaffected by the weight. Moreover, no bargaining power or real power exists.

- If $\frac{1}{2 v_{1}} \leq \alpha \leq 1-\frac{1}{2 v_{2}}$, formation of household $g$ is possible. Higher utilitarian power for an individual translates into higher bargaining power. However, only for individual 2 does higher bargaining power yield higher real power. For individual 1 , an increase in utilitarian and bargaining power yields a negative price effect, since the market value of the endowments of household $g$ decreases. For this individual, the negative price effect and an increase in his bargaining power offset each other exactly and his utility remains constant.

- If $\alpha>1-\frac{1}{2 v_{2}}$, individual 2 would leave the household and thus no bargaining or real power exists anymore.

Overall, we observe that there is no monotonic relationship between utilitarian power, bargaining power and real power.

\subsection{Shift of Power and Externalities}

One can further ask under what circumstances the social fabric is affected by a change of power within households. More specifically, the question is whether an equilibrium household structure persists after a shift of bargaining power within households. In the context of the current example, some straightforward answers can be given.

Fact 3 Some free exit equilibrium household structure can be upset by a shift of utilitarian power within households.

Fact 4 As long as there is any bargaining power at all, the free exit equilibrium household structure cannot be destroyed by a shift of bargaining power within households. 
The preceding discussion might suggest that an individual only has bargaining or real power if he can generate positive group externalities ("externality generator") for other household members or experience positive group externalities ("externality receiver") when forming a household with other individuals. Indeed, it is obvious that:

Fact 5 Suppose that an individual is neither an externality generator nor an externality receiver. Then his bargaining and real power in a two-person household is zero.

However, the same is no longer true in larger groups. Let us continue the example, but modify utility in the following way.

$$
\begin{aligned}
& U_{1}\left(x_{1}^{1}, x_{1}^{2}\right)= \begin{cases}x_{1}^{1}+v_{1} & \text { in case } h=\{1,2\} \text { or } h=\{1,2,3\} \text { with } \frac{1}{2} \geq v_{1} \geq 0 \\
x_{1}^{1} & \text { in all other cases }\end{cases} \\
& U_{2}\left(x_{2}^{1}, x_{2}^{2}\right)= \begin{cases}x_{2}^{2}+v_{2} & \text { in case } h=\{1,2\} \text { or } h=\{1,2,3\} \text { with } \frac{1}{2} \geq v_{2} \geq 0 \\
x_{2}^{2} & \text { in all other cases }\end{cases} \\
& U_{3}\left(x_{3}^{1}, x_{3}^{2}\right)=\frac{1}{2} x_{3}^{1}+\frac{1}{2} x_{3}^{2}
\end{aligned}
$$

There exists an equilibrium with free exit $(p ; \mathbf{x} ; P)$, given the household structure $P=\{\{1,2,3\}\}$, namely:

$$
p=(1,1), x_{1}=\left(1 / 2-v_{1}, 0\right), x_{2}=\left(0,1 / 2-v_{2}\right), x_{3}=\left(v_{1}+1 / 2, v_{2}+1 / 2\right) .
$$

Note that the allocation is an efficient choice of the sole household $h=\{1,2,3\}$ at the going prices. Moreover, markets clear. And neither individual 1 nor individual 2 can gain utility by leaving the household. Although individual $i=3$ is neither an externality generator nor an externality receiver, he has all the bargaining power and has real power. In fact he extracts all the surplus generated by the favorable externalities which individuals 1 and 2 generate by living together. His only contribution is that he does not destroy the externalities the other individuals in the group generate and receive.

Fact 6 Suppose that an individual is neither an externality generator nor an externality receiver. Then his bargaining and real power can be positive if he belongs to a household with more than two members. 
Of course, there are other equilibria with free exit in the above example where all three individuals have real power or in which the third individual is powerless.

\section{Power and Pareto Efficiency}

\subsection{Existence of CEFE}

The example in the previous section gives a first impression of the relationship between different concepts of power and equilibrium allocations in pure exchange economies with multi-person households. In the present section we begin a more systematic investigation of this relationship. For that purpose we first examine the structure of CEFE and subsequently draw conclusions about power. We focus on societies where groups either offer an advantage or a disadvantage to their members at any given price system. We consider a property called Large Group Advantage (LGA). Formally, the requirement LGA is captured by the following conditions $1-3$. To this end, we restrict prices to the simplex

$$
\Delta=\left\{p \in \mathbb{R}_{+}^{\ell}: \sum_{k=1}^{\ell} p^{k}=1\right\} .
$$

We denote the relative interior of $\Delta$ by $\Delta^{o}$. Further, let us choose $q>0$ so that the social endowment $\omega_{S}$ belongs to the cube $[0, q]^{\ell}$. Set $Q=[0,2 q]^{\ell}$. For a household $h$, put $K_{h}=\left\{\mathbf{x}_{\mathbf{h}}=\left(x_{i}\right)_{i \in h} \in \mathcal{X}_{h}: \sum_{i \in h} x_{i} \in Q\right\}$.

(LGA) Large Group Advantage: We say that a multi-member household $h$ has large group advantage if:

1. Every member $i \in h$ has a demand function $x_{i}^{0}(\cdot)$, where $x_{i}^{0}(p)$ denotes the demand of consumer $i$ when trading individually from the endowment $\omega_{\{i\}}$ at prices $p \in$ $\Delta^{o}$.

2. For every price system $p \in \Delta$, there exists a non-empty, compact and convex set $X_{h}(p) \subseteq B_{h}(p) \cap K_{h}$ which depends continuously on $p$.

3. For all $p \in \Delta^{o}$ and $\mathbf{x}_{\mathbf{h}} \in B_{h}(p) \cap K_{h}: \mathbf{x}_{\mathbf{h}} \in X_{h}(p)$ iff

$$
U_{i}\left(\mathbf{x}_{\mathbf{h}} ; h\right)-U_{i}\left(x_{i}^{0}(p) ;\{i\}\right) \geq \delta_{i}(p)
$$

with some threshold $\delta_{i}(p) \geq 0$ holds for all $i \in h$. 
4. For all $p \in \Delta, \mathbf{x}_{\mathbf{h}}, \mathbf{y}_{\mathbf{h}} \in B_{h}(p) \cap K_{h}$ :

$\mathbf{x}_{\mathbf{h}} \in X_{h}(p)$ and $U_{i}\left(\mathbf{y}_{\mathbf{h}} ; h\right) \geq U_{i}\left(\mathbf{x}_{\mathbf{h}} ; h\right)$ for all $i \in h$ implies $\mathbf{y}_{\mathbf{h}} \in X_{h}(p)$.

The key condition 2 is fulfilled for instance in the case of positive pure group externalities. Condition 3 implies condition 4 for $p \in \Delta^{o}$. But condition 4 is required to hold for all $p \in \Delta$.

Before formulating the existence theorem, we introduce two new concepts called strict monotonicity of household preferences and boundary aversion.

\section{Definition 1 (Strict Monotonicity (SM))}

The Strict Monotonicity property holds for household $h$ if for any two allocations $\mathbf{x}_{h}, \mathbf{y}_{h} \in \mathcal{X}_{h}$ with $\mathbf{y}_{h}>\mathbf{x}_{h}$ there exists an allocation $\mathbf{z}_{\mathbf{h}} \in \mathcal{X}_{h}$, such that ${ }^{4}$

$$
\sum_{i \in h} z_{i}=\sum_{i \in h} y_{i} \quad \text { and } \quad\left(U_{i}\left(\mathbf{z}_{\mathbf{h}} ; h\right)\right)_{i \in h} \gg\left(U_{i}\left(\boldsymbol{x}_{h} ; h\right)\right)_{i \in h} .
$$

Definition 2 (Boundary Aversion) Consumer $i \in I$ is boundary averse if for all $g, h \in \mathcal{H}_{i}, \mathbf{x}_{h}=\left(x_{j}\right)_{j \in h} \in \mathcal{X}_{h}, \mathbf{y}_{g}=\left(y_{j}\right)_{j \in g} \in \mathcal{X}_{g}$ :

$$
x_{i} \in \mathbb{R}_{++}^{\ell} \text { and } y_{i} \notin \mathbb{R}_{++}^{\ell} \text { implies } U_{i}\left(\mathbf{x}_{h} ; h\right)>U_{i}\left(\mathbf{y}_{g} ; g\right) \text {. }
$$

For completeness and later use we also state the concept of local non-satiation of multi-person households and the redistribution property which have been introduced in Gersbach and Haller (2001). Note that SM is neither implied by the redistribution property (RP) nor by local non-satiation of multi-member households.

Definition 3 A household $h$ is locally non-satiated if for every $\mathbf{x}_{\mathbf{h}} \in \mathcal{X}_{h}$ and every $\epsilon>0$, there exists $\mathbf{y}_{\mathbf{h}} \in \mathcal{X}_{h}$ with

$$
\left\|\mathbf{x}_{\mathbf{h}}-\mathbf{y}_{\mathbf{h}}\right\|_{|h| \ell}<\epsilon \text { and }\left(U_{i}\left(\mathbf{y}_{\mathbf{h}} ; h\right)\right)_{i \in h}>\left(U_{i}\left(\mathbf{x}_{\mathbf{h}} ; h\right)\right)_{i \in h} .
$$

Definition 4 (Redistribution Property (RP)) The Redistribution Property holds if for any household $h$ and any two allocations $\mathbf{x}_{\mathbf{h}}, \mathbf{y}_{\mathbf{h}} \in \mathcal{X}_{h}$ with $\left(U_{i}\left(\mathbf{y}_{\mathbf{h}} ; h\right)\right)_{i \in h}>\left(U_{i}\left(\mathbf{x}_{\mathbf{h}} ; h\right)\right)_{i \in h}$, there exists an allocation $\mathbf{z}_{\mathbf{h}} \in \mathcal{X}_{h}$ such that

$$
\sum_{i \in h} z_{i}=\sum_{i \in h} y_{i} \text { and }\left(U_{i}\left(\mathbf{z}_{\mathbf{h}} ; h\right)\right)_{i \in h} \gg\left(U_{i}\left(\mathbf{x}_{\mathbf{h}} ; h\right)\right)_{i \in h} .
$$

\footnotetext{
${ }^{4}$ The notation " $\gg$ " means that the strict inequality holds for each person.
} 
Now we present our first result, the existence of non-trivial CEFE.

Proposition 1 Suppose $P$ is a household structure and the following conditions hold:

(i) $\omega_{h} \gg 0$ for all $h \in \mathcal{H}$.

(ii) $U_{i}\left(\mathbf{x}_{\mathbf{h}} ; h\right)$ is continuous and concave in $\mathbf{x}_{\mathbf{h}} \in \mathcal{X}_{h}$ for all $i \in h, h \in \mathcal{H}$.

(iii) $U_{i}\left(x_{i} ;\{i\}\right)$ is strictly increasing in $x_{i} \in X_{i}$ for all $i \in I$.

(iv) LGA holds for all households $h \in P$ with $|h| \geq 2$.

(v) SM holds for some household $h \in P$ with $|h| \geq 2$.

Then there exists a competitive equilibrium with free exit of the form $(p, \mathbf{x} ; P)$.

The proof is given in the appendix. The proposition states that any household structure in which all individuals in all households can gain, at least in principle, from participating in the household, qualifies to be part of an equilibrium with free exit.

\subsection{CEFE, Power and Pareto Efficiency}

In this subsection, we are going to examine equilibria with free exit and, specifically, to look for Pareto efficiency and manifestation of power. We start with the following proposition.

Proposition 2 Suppose pure group externalities, that is $U_{i}\left(\mathbf{x}_{\mathbf{h}} ; h\right)=U_{i}^{c}\left(x_{i}\right)+U_{i}^{g}(h)$ for $\mathbf{x}_{\mathbf{h}} \in \mathcal{X}_{h}, h \in \mathcal{H}$. If

(i) $(p, \mathbf{x})$ is a competitive equilibrium of the pure exchange economy represented by $\left(U_{i}^{c}, \omega_{\{i\}}\right)_{i \in I}$, where all $U_{i}^{c}, i \in I$, satisfy local non-satiation, and

(ii) $P^{*}$ is the unique optimal household structure based solely on group preferences represented by $U_{i}^{g}, i \in I$,

then the state $\left(p, \mathbf{x} ; P^{*}\right)$ is a fully Pareto optimal CEFE and there does not exist another CEFE in which real power is higher for some individuals in their respective households and not less for any individual. 
The proof is given in the appendix. We illustrate Proposition 2 by means of an example.

\section{Example 2}

We can again use the main example 1 in section 4 . Clearly, the household structure $P^{*}=\{\{1,2\},\{3\}\}$ is the unique optimal household structure based solely on group preferences. The competitive equilibrium based solely on $U_{i}^{c}\left(x_{i}\right)$, where all individuals are singles, was given by $p^{0}=(1,1), x_{1}^{0}=\left(\frac{1}{2}, 0\right), x_{2}^{0}=\left(0, \frac{1}{2}\right)$ and $x_{3}^{0}=\left(\frac{1}{2}, \frac{1}{2}\right)$. Hence, real power, denoted by $\rho_{i}^{0}$, in the equilibrium $\left(p^{0}, \mathbf{x}^{0}, p^{*}\right)$ is given as:

$$
\begin{aligned}
& \rho_{1}^{0}=\ln \frac{1}{2}+\ln v_{1}-\ln \frac{1}{2}=\ln v_{1} \\
& \rho_{2}^{0}=\ln \frac{1}{2}+\ln v_{2}-\ln \frac{1}{2}=\ln v_{2} \\
& \rho_{3}^{0}=0
\end{aligned}
$$

In any other CEFE that can generate real power we must have $P=P^{*}$. As discussed in section 4 , equilibria with $P^{*}=\{\{1,2\},\{3\}\}$ have equilibrium prices $p^{*}=\left(1, \frac{1}{2 \alpha}\right)$ with $\alpha$ denoting the utilitarian weight of individual 1 in the household $\{1,2\}$ and $\alpha \in\left[\frac{1}{2 v_{1}}, 1-\frac{1}{2 v_{2}}\right]$. Hence, such equilibria generate real power of:

$$
\begin{aligned}
& \rho_{1}=\ln \frac{1}{2}+\ln v_{1}-\ln \left(\frac{1}{4 \alpha}\right) \\
& \rho_{2}=\ln (1-\alpha)+\ln v_{2}-\ln \frac{1}{2} \\
& \rho_{3}=0
\end{aligned}
$$

Hence, compared to $\left(p^{0}, \mathbf{x}^{0}, P^{*}\right)$ if $\rho_{1}$ is larger than $\rho_{1}^{0}\left(\right.$ i.e. if $\left.\alpha>\frac{1}{2}\right)$ then $\rho_{2}$ is smaller than $\rho_{2}^{0}$. Confirming Proposition 2, it is impossible that real power in a CEFE is larger for some individuals and not less for others than in $\left(p^{0}, \mathbf{x}^{0}, P^{*}\right)$.

Next we examine a more elaborate example: 


\section{Example 3}

Let $\ell=2, I=\{1,2,3\}$. The individual endowments are as in Examples 1 and 2 . Preferences are represented by $U_{i}\left(\mathbf{x}_{\mathbf{h}} ; h\right)=U_{i}\left(x_{i}\right)+U_{i}^{g}(h)$. Specifically, we assume

$$
\begin{aligned}
& U_{1}\left(x_{1}^{1}, x_{1}^{2}\right)= \begin{cases}\ln x_{1}^{1}+\ln v_{1} & \text { in cases } h=\{1,2\} \text { or } h=I, \text { with } v_{1} \geq 1 \\
\ln x_{1}^{1} & \text { in all other cases }\end{cases} \\
& U_{2}\left(x_{2}^{1}, x_{2}^{2}\right)= \begin{cases}\ln x_{2}^{2}+\ln v_{2} & \text { in cases } h=\{1,2\} \text { or } h=I, \text { with } v_{2} \geq 1 \\
\ln x_{2}^{2} & \text { in all other cases }\end{cases} \\
& U_{3}\left(x_{3}^{1}, x_{3}^{2}\right)= \begin{cases}\frac{1}{2} \ln x_{3}^{1}+\frac{1}{2} \ln x_{3}^{2}+\ln v_{3} & \text { in case } h=I, \text { with } v_{3} \geq 1 \\
\frac{1}{2} \ln x_{3}^{1}+\frac{1}{2} \ln x_{3}^{2} & \text { in all other cases }\end{cases}
\end{aligned}
$$

We first examine CEFE with $P=\{\{1,2\},\{3\}\}$. For that household structure, equilibria take the same form as in our main example 1 with $v_{3}=1$. We can maximize the power of individual 1 by setting $\alpha=1-\frac{1}{2 v_{2}}$, which leads to $p_{2}=\frac{v_{2}}{2 v_{2}-1}$ and we obtain real power in equilibrium as:

$$
\begin{aligned}
& \widehat{\rho}_{1}=\ln \frac{1}{2}+\ln v_{1}-\ln \left\{\frac{v_{2}}{4 v_{2}-2}\right\} \\
& \widehat{\rho}_{2}=\ln \left(\frac{1}{2 v_{2}}\right)+\ln v_{2}-\ln \frac{1}{2}=0 \\
& \widehat{\rho}_{3}=0
\end{aligned}
$$

We next look at equilibria for $P=\{I\}$. Note that this is the unique optimal household structure. The household $I$ is assumed to maximize the utilitarian welfare function

$$
W_{I}=\alpha_{1}\left(\ln x_{1}^{1}+\ln v_{1}\right)+\alpha_{2}\left(\ln x_{2}^{2}+\ln v_{2}\right)+\left(1-\alpha_{1}-\alpha_{2}\right)\left(\frac{1}{2} \ln x_{3}^{1}+\frac{1}{2} \ln x_{3}^{2}+\ln v_{3}\right)
$$

The excess demand vector is given by

$$
z_{I}=\left(\left(\alpha_{1}+\frac{1}{2}\left(1-\alpha_{1}-\alpha_{2}\right)\right)\left(p_{2}+1\right)-1, \frac{1}{p_{2}}\left(\alpha_{2}+\frac{1}{2}\left(1-\alpha_{1}-\alpha_{2}\right)\right)\left(p_{2}+1\right)-1\right)
$$

Market equilibrium yields

$$
p_{2}^{*}=\frac{1-\alpha_{1}+\alpha_{2}}{1+\alpha_{1}-\alpha_{2}}, 1+p_{2}^{*}=\frac{2}{1+\alpha_{1}-\alpha_{2}} .
$$


The parameters $\alpha_{1}, \alpha_{2}$ will be determined such that the exit conditions are fulfilled. The real power in equilibrium is given by

$$
\begin{aligned}
\rho_{1}^{*}= & \ln \left(\alpha_{1}\left(p_{2}^{*}+1\right)\right)+\ln v_{1}-\ln \left(\frac{1}{2} p_{2}^{*}\right) \\
\rho_{2}^{*}= & \ln \left(\alpha_{2} \frac{p_{2}^{*}+1}{p_{2}^{*}}\right)+\ln v_{2}-\ln \frac{1}{2} \\
\rho_{3}^{*}= & \frac{1}{2}\left\{\ln \left(\left(1-\alpha_{1}-\alpha_{2}\right) \frac{p_{2}^{*}+1}{2}\right)+\ln \left(\left(1-\alpha_{1}-\alpha_{2}\right) \frac{p_{2}^{*}+1}{2 p_{2}^{*}}\right)\right\}+\ln v_{3} \\
& -\frac{1}{2}\left\{\ln \frac{1}{2}+\ln \frac{1}{2 p_{2}^{*}}\right\}
\end{aligned}
$$

We obtain

Fact 7 Real power of individual 1 in a CEFE with $P=\{\{1,2\},\{3\}\}$ does not exceed the maximal real power of individual 1 in a CEFE with $P=\{I\}$. It $v_{3}>1$, then real power of individual 1 in a CEFE with $P=\{\{1,2\},\{3\}\}$ is less than the maximal real power of individual 1 in a CEFE with $P=\{I\}$.

The proof is given in the appendix.

One might conjecture that the intuition developed above extends to more general settings. In particular, one might expect that a CEFE, for which no other CEFE exists in which real power is weakly higher for all individuals, is fully Pareto optimal. This is an open question. But we do know from Gersbach and Haller (2003) that CEFE are not necessarily fully Pareto optimal. Therefore, one may ask when there exists a CEFE that is fully Pareto optimal. An interesting case where CEFE are fully Pareto optimal is the case of quasi-linear preferences to be explored in detail in section 6 .

\section{Quasi-linear Preferences and Spillovers}

In this section, we consider the special case of quasi-linear preferences. This case allows to illustrate our main propositions. It also serves to illustrate to what extent changes of bargaining power in one household affect other households. Such an effect is called power spillover. 


\subsection{Model}

We examine a society where $n=I / 2>1$ two-member households will be formed. Household $h=1, \ldots, n$ has members $h 1$ and $h 2$, called the first member and the second member. This household structure is denoted by $\widehat{P}$. There are $\ell>1$ goods. The consumption of good $k(k=1, \ldots, \ell)$ by individual $h i(i=1,2)$ is denoted $x_{h i}^{k}$. The vector $x_{h i}=\left(x_{h i}^{1}, \ldots, x_{h i}^{\ell}\right)$ denotes the consumption of household member $h i$. Each household $h$ is endowed with $w_{h}=\left(w_{h}^{1}, \ldots, w_{h}^{\ell}\right)$. The two members of household $h$ have quasi-linear utility representations, given by

$$
\begin{aligned}
& U_{h 1}\left(\mathbf{x}_{\mathbf{h}} ; h\right)=V_{h 1}\left(x_{h 1}^{1}, \ldots, x_{h 1}^{\ell-1}\right)+x_{h 1}^{\ell}+v_{1} \\
& U_{h 2}\left(\mathbf{x}_{\mathbf{h}} ; h\right)=V_{h 2}\left(x_{h 2}^{1}, \ldots, x_{h 2}^{\ell-1}\right)+x_{h 2}^{\ell}+v_{2}
\end{aligned}
$$

where $V_{h i}$ is assumed to be strictly concave and strictly increasing in $\left(x_{h i}^{1}, \ldots, x_{h i}^{\ell-1}\right)$. The parameters $v_{1}$ and $v_{2}\left(v_{1}>0, v_{2}>0\right)$ capture the group externalities that individuals $h 1$ and $h 2$ experience when living together. Living together with the same type of individual ${ }^{5}$ or in a household with more than two individuals is assumed to exert negative group externalities on everybody. Hence, such households will never be formed in a CEFE. Household $h$ maximizes

$$
S_{h}=\left\{U_{h 1}\left(x_{h 1}\right)-U_{h 1}\left(x_{h 1}^{0}(p)\right)\right\}^{\beta_{h}}\left\{U_{h 2}\left(x_{h 2}\right)-U_{h 2}\left(x_{h 2}^{0}(p)\right)\right\}^{1-\beta_{h}}
$$

subject to $U_{h 1}\left(x_{h 1}\right)-U_{h 1}\left(x_{h 1}^{0}(p)\right)>0$ and $U_{h 2}\left(x_{h 2}\right)-U_{h 2}\left(x_{h 2}^{0}(p)\right)>0$, where $0<\beta_{h}<1$ is the bargaining power of individual $h 1$ in household $h$. The functions $x_{h 1}^{0}(p)$ and $x_{h 2}^{0}(p)$ denote consumer $h 1$ 's and $h 2$ 's individual demand at the price system $p$ when they are singles.

\subsection{Equilibria, Power Shifts and Power Spillovers}

For the household structure $\widehat{P}$, we denote equilibrium values by $\widehat{x}_{h i}^{k}$, equilibrium utilities by $\widehat{U}_{h i}$ and $\widehat{V}_{h i}$ and the equilibrium prices by $\widehat{p}$. In the following, we assume that for any array of bargaining power parameters $\left(\beta_{1}, \ldots, \beta_{n}\right)$ under consideration: (a) Every household member consumes a non-negative amount of the numéraire good $\ell$ in every market equilibrium. (b) For the given household structure, the economy has a unique market equilibrium, up to price normalization. We obtain:

\footnotetext{
${ }^{5}$ That is, if members $h 1$ and $g 1$ of two different households $g \in \widehat{P}$ and $h \in \widehat{P}$ formed a new two-person household, both members would experience negative group externalities.
} 


\section{Proposition 3}

(i) $\frac{\partial \widehat{p}}{\partial \beta_{h}}=0$

(ii) $\frac{\partial \widehat{x}_{h 1}^{k}}{\partial \beta_{h}}=\frac{\partial \widehat{x}_{h 2}^{k}}{\partial \beta_{h}}=0 \quad \forall k=1, \ldots, \ell-1$

(iii) $\frac{\partial \widehat{x}_{h 1}^{\ell}}{\partial \beta_{h}}>0, \frac{\partial \widehat{x}_{h 2}^{\ell}}{\partial \beta_{h}}<0$

(iv) Suppose that households are homogeneous with respect to utility representations and endowments with $w_{h}=\bar{w}, \forall h=1, \ldots, n$. Then:

$$
\begin{aligned}
\widehat{x}_{h 1}^{\ell}=\beta_{h} \bar{w}^{\ell}+ & \beta_{h}\left\{\widehat{V}_{h 2}+v_{2}-U_{h 2}\left(x_{h 2}^{0}(\widehat{p})\right)\right\} \\
- & \left(1-\beta_{h}\right)\left\{\widehat{V}_{h 1}+v_{1}-U_{h 1}\left(x_{h 1}^{0}(\widehat{p})\right)\right\} \\
\widehat{x}_{h 2}^{\ell}=\left(1-\beta_{h}\right) \bar{w}^{\ell} & +\left(1-\beta_{h}\right)\left\{\widehat{V}_{h 1}+g_{1}-U_{h 1}\left(x_{h 1}^{0}(\widehat{p})\right)\right\} \\
- & \beta_{h}\left\{\widehat{V}_{h 2}+g_{2}-U_{h 2}\left(x_{h 2}^{0}(\widehat{p})\right)\right\}
\end{aligned}
$$

The proof is given in the appendix. As Proposition 3 illustrates, a change of bargaining power in household $h$ only influences the distribution of the numéraire in household $h$. Consumption of the first $\ell-1$ commodities and consumption in other households are not affected. We formulate this observation as

Corollary 1 A change of $\beta_{h}$ in a particular household h has no impact on individuals in other households.

The corollary states that there are no power spillovers in the case of quasi-linear preferences as bargaining power changes do not affect prices. This also means that a household $h$ cannot manipulate outcomes and possibly improve utility of household members at the expense of outsiders by misrepresenting internal bargaining power. ${ }^{6}$

Another immediate consequence of Propositions 2 and 3 and the proof of the latter is

\footnotetext{
${ }^{6}$ Makowski, Ostroy and Segal (1999) have comprehensively characterized continuous, efficient and anonymous incentive compatible mechanisms and have shown that such mechanisms must be perfectly competitive. Quasi-linear preferences are one of the examples that can allow for incentive compatible mechanisms or perfect competition. Our investigation shows that with quasi-linear preferences and the exit option a multi-person household has no incentive to misrepresent the internal bargaining power.
} 
Corollary 2 The equilibrium $(p, \mathbf{x}, \widehat{P})$ is a CEFE and fully Pareto optimal.

Namely, $\widehat{U}_{h 1}-U_{h 1}\left(x_{h 1}^{0}(\widehat{p})\right)>0$ and $\widehat{U}_{h 2}-U_{h 2}\left(x_{h 2}^{0}(\widehat{p})\right)>0$ are satisfied, since $v_{1}>0$ and $v_{2}>0$. Hence $(p, \mathbf{x}, \widehat{P})$ is a CEFE. Next, the pair $(p, \mathbf{x})$ is an equilibrium of the economy with single-person households and endowment allocation $\mathbf{x}$, since the individual first-order conditions for utility maximization are satisfied. Further, $\widehat{P}$ is an optimal household structure. Therefore, by Proposition $2,(\mathbf{x}, \widehat{P})$ is fully Pareto optimal.

\subsection{The Impact of Group Externalities}

In previous sections, we stressed the role of group externalities. Since the equilibrium is independent of the group externalities $v_{1}$ and $v_{2}$ as long as the exit conditions are fulfilled we obtain from Proposition 3:

\section{Corollary 3}

Suppose that households are homogeneous with respect to utility representations and endowments with $w_{h}=\bar{w}, \forall h=1, \ldots, n$. Then:
(i) $\frac{\partial \widehat{x}_{h 1}^{\ell}}{\partial v_{1}}<0, \frac{\partial \widehat{x}_{h 1}^{\ell}}{\partial v_{2}}>0$;
(ii) $\frac{\partial \widehat{x}_{h 2}^{\ell}}{\partial v_{2}}<0, \frac{\partial \widehat{x}_{h 2}^{\ell}}{\partial v_{1}}>0$;
(iii) $\frac{\partial \widehat{U}_{h i}}{\partial v_{i}}>0, \quad \frac{\partial \widehat{U}_{h i}}{\partial v_{j}}>0, \quad i \neq j$.

Hence, if individual $h 1$ gains relatively more from living in household $h$, i.e. when $v_{1}$ increases, he receives less of the numéraire good. But the net effect on utility is positive. Since equilibrium prices are not affected, real power of both individuals increases when $v_{1}$ is higher. 


\section{Applications and Extensions}

While our analysis has primarily been focused on the three concepts of power, fruitful extensions in a variety of directions are possible and illustrated in this section by way of examples.

\subsection{Human Relations Paradoxes}

In this subsection we illustrate certain human relations paradoxes where the nonconsumptive, e.g. emotional benefits from household formation increase, but none of the household members gains in equilibrium.

For this purpose we reconsider the example of section 4. Conventional wisdom has it that if a party has all the bargaining power, it can extract all the surplus from a relationship. Consequently, if the surplus increases, this party should benefit. This logic also applies here. If consumer 1 exerts total bargaining power, $\beta=1$, then he can extract all the surplus created by household $h$ up to the point where consumer 2 is indifferent between staying in the household and leaving. So let us assume $\beta=1$. Now suppose that $v_{2}$, the amount of positive group externality which consumer 1 exerts on consumer 2 increases, so that for whatever reasons consumer 2 derives more social or emotional benefit from having consumer 1 around. Would consumer 1 gain from such a change? Ceteris paribus, their total surplus would increase and, by the above logic, consumer 1 would be the sole beneficiary. But it turns out that neither consumer 1 nor 2 benefits if a corresponding equilibrium price adjustment occurs.

Notice that we assume $\beta \equiv 1$. Hence $\alpha=\bar{\alpha}=1-\frac{1}{2 v_{2}}$. The upper bound $\bar{\alpha}$ is increasing in $v_{2}$. Therefore, the equilibrium price $p^{*}=1 /(2 \bar{\alpha})$ declines in $v_{2}$. Indifference of consumer 2 between staying and leaving requires $\ln \left(x_{2}^{*}\right)+\ln v_{2}=\ln (1 / 2)$ which amounts to $x_{2}^{*}=1 /\left(2 v_{2}\right)$. As $v_{2}$ increases, more of the household endowment of good 2 will be sold in exchange for good 1 . But because of the decline of the equilibrium price $p_{2}^{*}$, consumer 1 cannot afford more than the previous consumption level $x_{1}^{*}$.

Hence, there is the paradoxical situation that an increase in positive group externalities does not translate into higher utility for any of the household members. The only one to gain is consumer 3 , whose equilibrium utility goes up. This is not always so. Still with $\beta \equiv 1$ in the example in section 4 , the benefits from an increase of $v_{1}$ accrue solely 
to consumer 1 . With $\beta \equiv 0$, we obtain $\alpha=\underline{\alpha}$. If $v_{1}$ increases, both consumer 1 (due to higher group externalities $\ln v_{1}$ ) and consumer 2 (due to full bargaining power) share in the gain to the detriment of consumer 3. If $v_{2}$ increases, the benefits accrue solely to consumer 2 .

Finally, let us consider the case of equal bargaining power, $\beta \equiv 1 / 2$. Then $\frac{\beta}{1-\beta}=1$ and by (5),

$$
\begin{gathered}
\frac{\alpha}{1-\alpha}\left[\ln \alpha+\ln \left(2 v_{1}\right)\right]=\ln (1-\alpha)+\ln \left(2 v_{2}\right) \quad \text { or } \\
\ln \left(2 v_{1}\right)=\left(\frac{1}{\alpha}-1\right) \ln (1-\alpha)+\left(\frac{1}{\alpha}-1\right) \ln \left(2 v_{2}\right)-\ln \alpha
\end{gathered}
$$

Moreover, $\alpha \in(\underline{\alpha}, \bar{\alpha})$. If $v_{1}$ increases, then $\alpha$ must decrease to preserve the equation. As a result, consumers 1 and 2 both gain at the detriment of consumer 3 . If $v_{2}$ increases, then $\alpha$ must increase in order to preserve the equation. Hence consumer 3 gains, consumer 2 loses in terms of utility from consumption but gains in terms of group externalities, and consumer 1 is unaffected by the increased group externality - another paradoxical outcome.

The paradoxes occur because of a drastic price effect in response to preference changes, whereas in a typical large economy, a small household can only cause negligible price effects. However, a sufficiently widespread change of consumer characteristics can have drastic price effects also in a large economy. For instance, our conclusions immediately generalize to the case of a replica economy where consumers 1, 2, and 3 are replaced by respective consumer types 1,2,3 and there is the same number of consumers of each type.

\subsection{Implicit and Determinate Power}

The efficient collective choice condition, $\mathbf{x}_{\mathbf{h}} \in E B_{h}(p)$, does not require each household to have a utilitarian social welfare function that it maximizes to reach efficient decisions. It need not maximize a Nash product either. Indeed, a household need not maximize any numerical objective function at all to arrive at efficient decisions. For example, a household $h$ may adhere to a hierarchical rule and proceed as follows. First maximize $U_{1}\left(\mathbf{x}_{\mathbf{h}} ; h\right)$ subject to $\mathbf{x}_{\mathbf{h}} \in B_{h}(p)$, with value $\bar{U}_{1}$. Next maximize $U_{2}\left(\mathbf{x}_{\mathbf{h}} ; h\right)$ subject to $\mathbf{x}_{\mathbf{h}} \in B_{h}(p)$ and $U_{1}\left(\mathbf{x}_{\mathbf{h}} ; h\right)=\bar{U}_{1}$, with value $\bar{U}_{2}$, and so on. Does this mean that all the appealing power concepts are gone? Not completely, since one can ask, for example, 
which utilitarian social welfare weights would have lead the household to make the same decision. Hence, we can talk about the implicit power behind an efficient collective household decision.

With explicit and implicit power, we face the fundamental question of what the determinants of power within the household are, given that the concept of competitive equilibrium with free exit per se leaves power indeterminate. In this subsection, we show how the determinants of power can be divided into a personal component (personality attributes broadly defined) and an equilibrium component (specific to the equilibrium ultimately realized).

Suppose that the balance of power within a household might be determined by a personality profile, $\pi^{h}=\left(\pi_{i}\right)_{i \in h}$, of the household members, where each $\pi_{i}$ represents the personality attributes of individual $i$. Let $\Pi^{h}$ denote the set of conceivable personality profiles for household $h$. Let us assume that a personality profile translates into efficient decisions for the household as follows. Formally, there is a mapping

$$
\mathcal{R}^{h}: \mathbb{R}^{\ell} \times \Pi^{h} \rightarrow \mathcal{X}_{h}
$$

with $\mathcal{R}^{h}\left(p, \pi^{h}\right) \in E B_{h}(p)$ for any price system $p$ and personality profile $\pi^{h}$. For a fixed profile $\pi^{h}$, we will simply work with the reduced form $R^{h}(\cdot)=\mathcal{R}^{h}\left(\pi^{h}, \cdot\right)$. The latter is merely a reflection of our static model and ignores the fact that perceived or actual personalities may change over time. Depending on the household's personality profile, the efficient decision rule $R^{h}$ may assume many forms, for example:

- $R^{h}$ can be a utilitarian rule with weights $\alpha_{i}^{h}, i \in h$.

- $R^{h}$ can be a Nash-bargaining rule with bargaining powers $\beta_{i}^{h}, i \in h$.

- $R^{h}$ can be the hierarchical rule depicted earlier.

- $R^{h}$ can be the "Rawlsian rule" that maximizes the minimum utility among household members subject to efficiency.

No matter what the rule, the household will make a determinate choice $\mathbf{x}_{\mathbf{h}}=R^{h}(p)$ at equilibrium prices which determines, explicitly or implicitly, the "utilitarian", "bargaining" and "real" power within the household. The remaining indeterminacy is due to multiplicity of equilibria. To see this, consider a multi-member household $h$ whose 
efficient decision rule is a Nash-bargaining rule with bargaining powers $\beta_{i}^{h}, i \in h$. Then to the extent that this household is formed, the "bargaining" power of member $i$ is trivially $\beta_{i}=\beta_{i}^{h}$ and independent of the particular equilibrium. But "utilitarian power" can vary across equilibria. For example, suppose that there are two equilibria where this household is formed, one with equilibrium price system $p$, the other with equilibrium price system $p^{\prime}$, and that $p$ and $p^{\prime}$ are not collinear. Since in the household's bargaining problem, both the feasible set of utility allocations and the reservation utilities are price-sensitive, typically $R^{h}(p) \neq R^{h}\left(p^{\prime}\right)$. But then, as a rule, the implied distribution of "utilitarian" power within the household differs across the two equilibria.

Now consider instead a household $h$ whose efficient decision rule is utilitarian with weights $\alpha_{i}^{h}, i \in h$. This keeps "utilitarian" power within the household constant whereas "bargaining" power may differ across equilibria. Incidentally, this cannot happen to household $g=\{1,2\}$ in subsection 5.1, since the right-hand side of (5) depends only on exogenous variables. Let us therefore present another example.

Example 5 Let $\ell=2, I=\{1,2,3,4\}$. Let $x_{i}^{k}$ denote the amount of good $k=1,2$ consumed by person $i=1,2,3,4$. We consider the two two-person households $g=$ $\{1,2\}$ and $h=\{3,4\}$. Preferences are represented by utility functions $U_{i}, i \in I$, with the following pure group externalities:

$$
\begin{aligned}
& U_{1}\left(x_{1}^{1}, x_{1}^{2}\right)=\ln x_{1}^{1} \quad \text { regardless of household membership } \\
& U_{2}\left(x_{2}^{1}, x_{2}^{2}\right)= \begin{cases}\ln x_{2}^{2}+\ln 2 & \text { in case } g \text { is formed } \\
\ln x_{2}^{2} & \text { in all other cases }\end{cases} \\
& U_{3}\left(x_{3}^{1}, x_{3}^{2}\right)=\ln x_{3}^{1} \text { regardless of household membership } \\
& U_{4}\left(x_{4}^{1}, x_{4}^{2}\right)= \begin{cases}\ln x_{4}^{2}+\ln 2 & \text { in case } h \text { is formed } \\
\ln x_{4}^{2} & \text { in all other cases }\end{cases}
\end{aligned}
$$

The individual endowments are $\omega_{1}=(0,1), \omega_{2}=(0,2), \omega_{3}=(0,1), \omega_{4}=(4,0)$. We further assume $\alpha_{1}^{g}=\alpha_{2}^{g}=\alpha_{3}^{h}=\alpha_{4}^{h}=1 / 2$. Let us compare for this economy the two equilibria $E=(p, \mathbf{x}, P)$ and $E^{\prime}=\left(p^{\prime}, \mathbf{x}^{\prime}, P^{\prime}\right)$ given by $P=\{g, h\}, P^{\prime}=\{\{1\},\{2\}, h\}$, and

$$
\begin{aligned}
& p=(1,1), \quad x_{1}=(1.5,0), \quad x_{2}=(0,1.5), \quad x_{3}=(2.5,0) \quad x_{4}=(0,2.5) ; \\
& p^{\prime}=(1,4 / 3), \quad x_{1}^{\prime}=(4 / 3,0), \quad x_{2}^{\prime}=(0,2), \quad x_{3}^{\prime}=(8 / 3,0), \quad x_{4}^{\prime}=(0,2) .
\end{aligned}
$$

Next suppose that at an equilibrium price system of the form $p^{*}=\left(1, p_{2}\right)$, the household 
$h$ reaches the same decision when maximizing a Nash product, where the relative bargaining power equals $\beta_{3}^{h}=\beta, \beta_{4}^{h}=1-\beta$. The values of the exit options are $U_{3}^{0}=$ $\ln p_{2}$ and $U_{4}^{0}=\ln \left(4 / p_{2}\right)$. Using the household budget constraint $x_{4}^{2}=\left(4+p_{2}-x_{3}^{1}\right) / p_{2}$, the first order condition amounts to:

$$
\frac{\beta}{1-\beta}=\frac{x_{3}^{1}}{4+p_{2}-x_{3}^{1}} \cdot \frac{\ln x_{3}^{1}-\ln p_{2}}{\ln \left(4+p_{2}-x_{3}^{1}\right)-\ln 2} .
$$

Now at $E$, we obtain $\beta /(1-\beta)=4.106$ and $\beta=0.804$. And at $E^{\prime}$, we obtain $\beta^{\prime} /\left(1-\beta^{\prime}\right)=2.409$ and $\beta^{\prime}=0.707$. We can also calculate the "real power" of 3 and 4 in each equilibrium. Then the comparison turns out as follows:

\begin{tabular}{|l|cccc|}
\hline & 3 at $E$ & 3 at $E^{\prime}$ & 4 at $E$ & 4 at $E^{\prime}$ \\
\hline utilitarian power & $1 / 2$ & $1 / 2$ & $1 / 2$ & $1 / 2$ \\
bargaining power & 0.804 & 0.707 & 0.196 & 0.293 \\
real power & 0.916 & 0.693 & 0.223 & 0.288 \\
\hline
\end{tabular}

The example illustrates that bargaining and real power differ across equilibria even though utilitarian power remains constant. For ease of computation, we have looked at two equilibria, $E$ and $E^{\prime}$, with different household structures, $P$ and $P^{\prime}$. In more complex economies, we could find examples with $P=P^{\prime}$, for there might exist multiple competitive equilibria with free exit and identical household structures, but different equilibrium allocations and relative prices, and therefore different degrees of power.

\subsection{De jure and de facto Power}

Household members are not able to exit in all cases even though they would do better alone. In fact a household member may be deprived of any right of decision. Thus it has no direct influence on the household's consumption decision and lacks freedom of association. It never decided to join this household. It is not allowed to leave the household without the consent of others. Even if it had permission, it could not afford to leave because of lack of independent resources. Therefore, it does not have a serious exit threat. This is most obvious for children. If the exit threat is de jure not possible for a subset of individuals, our equilibrium concept can be modified accordingly. This allows us to distinguish further between de jure and de facto power. Suppose that 
a subset $I^{o}$ in the set of all individuals $I$ has no right to leave a household. Then condition 3 of a competitive equilibrium with free exit becomes:

3. There is no $h \in P, i \in h, i \in I \backslash I^{0}$ and $y_{i} \in B_{\{i\}}(p)$ such that

$$
U_{i}\left(y_{i} ;\{i\}\right)>U_{i}\left(\mathbf{x}_{\mathbf{h}} ; h\right)
$$

The notion of utilitarian power can be defined accordingly for dependent persons, i.e. persons in the subset $I^{0}$ and may also be called de facto power. The notions of bargaining power and real power, however, require de jure power and are no longer defined.

De jure powerless people can have de facto power. For instance, the young enfant terrible who terrorizes the rest of the family may benefit a lot from de facto power. First, the negative group externalities caused by the kid can be weakened by offering him prodigal consumption as a bribe for good behavior. Note that in this case, the externalities from belonging to a group and utilities from consumption cannot be separated any longer. Second, the rest of the household may have or feel a fiduciary duty towards the youngster so that the welfare or consumption of the kid causes some positive externality for the rest of the household. Finally, out of sheer self-interest the rest of the household may devote resources to the child's upbringing (Becker (1993)): For example, parents worried about old-age support may try to instill in their children feelings of guilt, obligation, duty, and filial love that indirectly, but still very effectively, can "commit" children to helping them out.

\section{Conclusion}

In this paper we have presented several ideas how to identify different forms of power in general equilibrium. The paper offers a sequence of concepts, examples and applications. Each part of the paper can be extended and deepened - which promises a host of future research topics. 


\section{$9 \quad$ Appendix}

\section{Proof of Proposition 1}

We apply the construction in the proof in Gersbach and Haller (2003) to all households. Specifically, each household $h \in P$ is assumed to maximize, for each $p \in \Delta$, its aggregate welfare $W_{h}$ defined as

$$
W_{h}\left(\mathbf{x}_{\mathbf{h}}\right)=\sum_{i \in h} U_{i}\left(\mathbf{x}_{\mathbf{h}} ; h\right)
$$

on its restricted budget set $X_{h}(p)$. Following the logic of Gersbach and Haller (2003), the household's aggregate demand correspondence $D_{h}(\cdot)$ is u.h.c. for all $h \in P$. Aggregation across households in $P$ yields that $\Phi(\cdot)$, the market excess demand relation resulting from reduced budget sets is non-empty-valued, convex-valued, u.h.c., and satisfies the strong form of Walras' law. By Theorem 6.37 of Ellickson (1993), there exists a pair $(p, \mathbf{z}) \in \Delta \times \mathbb{R}^{\ell}$ with

(a) $\mathbf{z} \in \Phi(p)$ and

(b) $\mathbf{z} \leq 0$ and $\mathbf{z}=0$ whenever $p \gg 0$.

Condition (a) means that

$$
\mathbf{z}=\sum_{g \in P} \mathbf{d}_{\mathbf{g}}-\omega_{S}
$$

where $\mathbf{d}_{\mathbf{g}} \in D_{g}(p)$ for each $g \in P$.

By the following observation we can rule out that a price is zero. Suppose the quasiequilibrium price $p_{k^{*}}=0$ for some $k^{*}, 1 \leq k^{*} \leq \ell$. Let us consider a household $h$ for which $|h| \geq 2$ and $S M$ holds. According to our construction, $\mathbf{d}_{\mathbf{h}}=\sum_{i \in h} x_{i}$ where $\mathbf{x}_{\mathbf{h}}=\left(x_{i}\right)_{i \in h}$ maximizes $W_{h}$ on $X_{h}(p)$. Moreover, $\mathbf{d}_{\mathbf{h}} \leq \sum_{g \in P} \mathbf{d}_{\mathbf{g}} \leq \omega_{S} \in[0, q]^{\ell}$. Therefore, $\mathbf{y}_{\mathbf{h}} \in \mathcal{X}_{h}$, defined by

$$
\begin{aligned}
y_{i}^{k} & =x_{i}^{k}, & & 1 \leq k \leq \ell, k \neq k^{*}, \\
y_{i}^{k^{*}} & =x_{i}^{k^{*}}+\Delta, & & k=k^{*},
\end{aligned}
$$

for all $i \in h$, with some suitably chosen $\Delta>0$, belongs to $B_{h}(p) \cap K_{h}$ and satisfies $\mathbf{y}_{\mathbf{h}}>\mathbf{x}_{\mathbf{h}}$. Since $S M$ holds for household $h$, there exists $\mathbf{y}_{\mathbf{h}}^{\prime} \in B_{h}(p) \cap K_{h}$ such that 
$\left(U_{i}\left(\mathbf{y}_{\mathbf{h}}^{\prime} ; h\right)\right)_{i \in h} \gg\left(U_{i}\left(\mathbf{x}_{\mathbf{h}} ; h\right)\right)_{i \in h}$. But then $W_{h}\left(\mathbf{y}_{\mathbf{h}}^{\prime}\right)>W_{h}\left(\mathbf{x}_{\mathbf{h}}\right)$, a contradiction. Hence, to the contrary, $p \gg 0$.

Therefore, we have $\mathbf{z}=0$. Next, a standard argument shows that each $\mathbf{x}_{\mathbf{h}}$ maximizes $W_{h}$ on $B_{h}(p)$. Thus, $\mathbf{x}_{\mathbf{h}} \in E B_{h}(p)$. Finally, from the characterization of $X_{h}(p)$ in LGA, no individual wants to exit a household $h \in P$ and $(p ; \mathbf{x} ; P)$ is a competitive equilibrium with free exit.

\section{Proof of Proposition 2}

For $i \in I$ and $P \in \mathcal{P}$, let $P(i)$ denote the household to which $i$ belongs in the household structure $P$.

First, we show that $\left(\mathbf{x} ; P^{*}\right)$ is a fully Pareto optimal allocation. For suppose not. Then there exists a feasible allocation $(\mathbf{y} ; P)$ such that $U_{i}\left(y_{i} ; P(i)\right)>U_{i}\left(x_{i} ; P^{*}(i)\right)$ for some $i \in I$ and $U_{i}\left(y_{i} ; P(i)\right) \geq U_{i}\left(x_{i} ; P^{*}(i)\right)$ for all $i \in I$. Since $(p, \mathbf{x})$ is a competitive equilibrium of the pure exchange economy $\left(U_{i}^{c}, \omega_{\{i\}}\right)_{i \in I}$ and consumers are locally nonsatiated, $\mathbf{x}$ is a Pareto optimal allocation of the pure exchange economy. Therefore, if it is the case that $U_{i}^{c}\left(y_{i}\right)>U_{i}^{c}\left(x_{i}\right)$ for some $i$, then $U_{j}^{c}\left(y_{j}\right)<U_{j}^{c}\left(x_{j}\right)$ and, consequently, $U_{j}^{g}(P(j))>U_{j}^{g}\left(P^{*}(j)\right)$ for some $j \neq i$. If it is the case that $U_{i}^{c}\left(y_{i}\right) \leq U_{i}^{c}\left(x_{i}\right)$ for all $i$, then $U_{j}^{g}(P(j))>U_{j}^{g}\left(P^{*}(j)\right)$ for some $j$. In any case, $U_{j}^{g}(P(j))>U_{j}^{g}\left(P^{*}(j)\right)$ for some $j$. But then there exists an optimal household structure $P^{\prime}$ such that $U_{j}^{g}\left(P^{\prime}(j)\right) \geq$ $U_{j}^{g}(P(j))>U_{j}^{g}\left(P^{*}(j)\right)$ and, consequently, $P^{\prime} \neq P^{*}$, contradicting (ii).

Second, we show that $\left(p, \mathbf{x} ; P^{*}\right)$ is a CEFE. Let $i \in I$. Since $(p, \mathbf{x})$ is a competitive equilibrium of the pure exchange economy $\left(U_{i}^{c}, \omega_{\{i\}}\right)_{i \in I}$ and pure group externalities prevail, the first two conditions for a CEFE hold. Moreover:

(a) Since $(p, \mathbf{x})$ is a competitive equilibrium of the pure exchange economy $\left(U_{i}^{c}, \omega_{\{i\}}\right)_{i \in I}$, $x_{i}$ is an optimal consumption bundle in $i$ 's budget set.

(b) Since $P^{*}$ is the unique optimal household structure, $U_{i}^{g}(\{i\}) \leq U_{i}^{g}\left(P^{*}(i)\right)$, by the argument given before.

Hence $i$ cannot fare better as a one-person household. Thus the third condition for a CEFE holds as well. 
Third, we show that there does not exist another CEFE in which real power is higher for some individuals in their respective households and not lower for any individual. Namely, suppose that there exists a $\operatorname{CEFE}\left(p^{\prime}, \mathbf{y} ; P^{\prime}\right)$ in which real power is higher for some individuals and not lower for any individual than in $\left(p, \mathbf{x} ; P^{*}\right)$. Hence,

$$
U_{i}^{c}\left(y_{i}\right)+U_{i}^{g}\left(P^{\prime}(i)\right)-U_{i}^{c}\left(x_{i}^{0}\left(p^{\prime}\right)\right) \geq U_{i}^{c}\left(x_{i}\right)+U_{i}^{g}\left(P^{*}(i)\right)-U_{i}^{c}\left(x_{i}^{0}(p)\right)
$$

for all $i$, with strict inequality for some $i$. As $P^{*}$ is unique, we obtain $U_{i}^{g}\left(P^{\prime}(i)\right) \leq$ $U_{i}^{g}\left(P^{*}(i)\right)$ for all $i$ by a previous argument. Therefore,

$$
U_{i}^{c}\left(y_{i}\right)-U_{i}^{c}\left(x_{i}^{0}\left(p^{\prime}\right)\right) \geq U_{i}^{c}\left(x_{i}\right)-U_{i}^{c}\left(x_{i}^{0}(p)\right)=0
$$

for all individuals $i$ with strict inequality for some $i$. Now pick $j \in I$ with $U_{j}^{c}\left(y_{j}\right)>$ $U_{j}^{c}\left(x_{j}^{0}\left(p^{\prime}\right)\right)$. If $p^{\prime} y_{i}<p^{\prime} \omega_{\{i\}}$ for some $i \in P^{\prime}(j)$, then local non-satiation implies $U_{i}^{c}\left(x_{i}^{0}\left(p^{\prime}\right)\right)>U_{i}^{c}\left(y_{j}\right)$, contradicting $U_{i}^{c}\left(y_{i}\right) \geq U_{i}^{c}\left(x_{i}^{0}\left(p^{\prime}\right)\right)$. Therefore, $p^{\prime} y_{i} \geq p^{\prime} \omega_{\{i\}}$ for all $i \in P^{\prime}(j)$. Since $\mathbf{y}_{P^{\prime}(j)} \in E B_{P^{\prime}(j)}\left(p^{\prime}\right)$, this implies $p^{\prime} y_{i}=p^{\prime} \omega_{\{i\}}$ and, consequently, $U_{i}^{c}\left(y_{i}\right) \leq U_{i}^{c}\left(x_{i}^{0}\left(p^{\prime}\right)\right)$ for all $i \in P^{\prime}(j)$. Thus a contradiction to $U_{j}^{c}\left(y_{j}\right)>U_{j}^{c}\left(x_{j}^{0}\left(p^{\prime}\right)\right)$ results. Hence, to the contrary, it cannot be the case that in the $\operatorname{CEFE}\left(p^{\prime}, \mathbf{y} ; P^{\prime}\right)$, real power is higher for some individuals and not lower for any individual than in $\left(p, \mathbf{x} ; P^{*}\right)$.

\section{Proof of Fact 7}

STEP 1: We first examine the non-exit conditions in case $P=\{I\}$. For the first individual we obtain:

$$
\ln \left(\alpha_{1}\left(p_{2}^{*}+1\right)\right)+\ln v_{1} \geq \ln \left(\frac{1}{2} p_{2}^{*}\right)
$$

which is equivalent to $\alpha_{1} \geq \frac{p_{2}^{*}}{2\left(p_{2}^{*}+1\right) v_{1}}$ and $\alpha_{1} \geq \frac{1+\alpha_{2}}{4 v_{1}+1}$.

Similarly, for the second individual we obtain

$$
\ln \left(\alpha_{2} \frac{p_{2}^{*}+1}{p_{2}^{*}}\right)+\ln v_{2} \geq \ln \frac{1}{2}
$$

or $\alpha_{2} \geq \frac{p_{2}^{*}}{\left(p_{2}^{*}+1\right) 2 v_{2}}$ which is equivalent to $\alpha_{2} \geq \frac{1-\alpha_{1}}{4 v_{2}-1}$.

Finally, the third individual's non-exit condition amounts to

$\frac{1}{2}\left\{\ln \frac{1}{2}+\ln \frac{1}{2 p_{2}^{*}}\right\} \leq \frac{1}{2} \ln \left(\left(1-\alpha_{1}-\alpha_{2}\right) \frac{p_{2}^{*}+1}{2}\right)+\frac{1}{2} \ln \left(\left(1-\alpha_{1}-\alpha_{2}\right) \frac{p_{2}^{*}+1}{2 p_{2}^{*}}\right)+\ln v_{3}$ 
which implies $\left(1-\alpha_{1}-\alpha_{2}\right)\left(p_{2}^{*}+1\right) \geq 1 / v_{3}$ or $1-\alpha_{1}-\alpha_{2} \geq\left(1+\alpha_{1}-\alpha_{2}\right) /\left(2 v_{3}\right)$ which finally is equivalent to $\alpha_{1} \leq \frac{2 v_{3}-1}{2 v_{3}+1} \cdot\left(1-\alpha_{2}\right)$.

STEP 2: We next examine whether real power of individual $I$ can be equal or higher under the household structure $P=\{\{1,2\},\{3\}\}$ than under $P=\{I\}$, i.e. we examine whether it is possible to delineate parameter values such that $\widehat{\rho_{1}} \geq \max \left\{\rho_{1}^{*}\right\}$. The inequality is equivalent to

$$
\ln \left(\frac{4 v_{2}-2}{2 v_{2}}\right) \geq \max \left\{\ln \left(\frac{2 \alpha_{1}\left(1+p_{2}^{*}\right)}{p_{2}^{*}}\right)\right\}
$$

which implies

$$
\frac{4 v_{2}-2}{2 v_{2}} \geq \max \left\{\frac{4 \alpha_{1}}{1-\alpha_{1}+\alpha_{2}}\right\}
$$

In order to maximize $\rho_{1}^{*}$ we therefore obtain the following problem:

$$
\max _{\alpha_{1} \in[0,1]}\left\{\frac{4 \alpha_{1}}{1-\alpha_{1}+\alpha_{2}}\right\}
$$

s.t.

$$
\begin{aligned}
& \alpha_{2} \geq \frac{1-\alpha_{1}}{4 v_{2}-1} \\
& \alpha_{1} \leq \frac{2 v_{3}-1}{2 v_{3}+1} \cdot\left(1-\alpha_{2}\right)
\end{aligned}
$$

It follows that the optimal solution for $\alpha_{2}$ is given by $\alpha_{2}=\frac{1-\alpha_{1}}{4 v_{2}-1}$ since $\frac{\partial \rho_{1}^{*}}{\partial \alpha_{2}}<0, \frac{\partial \rho_{1}^{*}}{\partial \alpha_{1}}>0$ and the right hand side of the last constraint is monotonically decreasing in $\alpha_{2}$. Hence our problem is reduced to

$$
\max _{\alpha_{1} \in[0,1]}\left\{\frac{\left(4 v_{2}-1\right) \alpha_{1}}{v_{2}\left(1-\alpha_{1}\right)}\right\}
$$

where the constraint amounts to

$$
\left(2 v_{3}+1\right) \alpha_{1} \leq\left(2 v_{3}-1\right) \cdot\left(1-\frac{1-\alpha_{1}}{4 v_{2}-1}\right)
$$

which leads to

$$
\alpha_{1} \leq \frac{\left(2 v_{2}-1\right)\left(2 v_{3}-1\right)}{2\left(v_{2}-v_{3}+2 v_{3} v_{2}\right)}<1
$$

Hence, maximization of $\rho_{1}^{*}$ is obtained by

$$
\alpha_{1}=\frac{\left(2 v_{2}-1\right)\left(2 v_{3}-1\right)}{2\left(v_{2}-v_{3}+2 v_{3} v_{2}\right)}
$$


Now based on the foregoing transformation, the inequality $\widehat{\rho_{1}} \geq \max \left\{\rho_{1}^{*}\right\}$ leads to

$$
\frac{4 v_{2}-2}{2 v_{2}} \geq \frac{\left(4 v_{2}-1\right) \alpha_{1}}{v_{2}\left(1-\alpha_{1}\right)}
$$

which implies $\alpha_{1} \leq \frac{2 v_{2}-1}{6 v_{2}-2}$. Hence, $\widehat{\rho_{1}} \geq \max \left\{\rho_{1}^{*}\right\}$ yields

$$
\frac{\left(2 v_{2}-1\right)\left(2 v_{3}-1\right)}{2\left(v_{2}-v_{3}+2 v_{2} v_{3}\right)} \leq \frac{2 v_{2}-1}{6 v_{2}-2}
$$

which implies $4 v_{3} v_{2}-4 v_{2}-v_{3} \leq-1$ or $4 v_{2}\left(v_{3}-1\right) \leq v_{3}-1$.

In case $v_{3}>1$, the latter implies $4 v_{2} \leq 1$ which contradicts $v_{2} \geq 1$ and, therefore, $\widehat{\rho_{1}}<\max \left\{\rho_{1}^{*}\right\}$ has to hold.

In case $v_{3}=1, \widehat{\rho_{1}}>\max \left\{\rho_{1}^{*}\right\}$ would yield $0=4 v_{2}\left(v_{3}-1\right)<v_{3}-1=0$ and, thus, $0<0$; therefore, $\widehat{\rho_{1}} \leq \max \left\{\rho_{1}^{*}\right\}$ has to hold.

Hence, there are no parameter constellations such that the maximal power of individual 1 in a CEFE with $P=I$ is strictly smaller than $\widehat{\rho_{1}}$.

\section{Proof of Proposition 3}

Good $\ell$ serves as a numéraire so that the price system assumes the form $\left(p_{1}, \ldots, p_{\ell-1}, 1\right)$. We consider the first-order conditions of maximizing $\ln S_{h}$ in household $h:^{7}$

$$
\begin{aligned}
\beta_{h} \frac{1}{U_{h 1}-U_{h 1}\left(x_{h 1}^{0}(p)\right)} \frac{\partial V_{h 1}}{\partial x_{h 1}^{k}}-\lambda_{h} p_{k} & =0, \quad k=1, \ldots, \ell-1 \\
\beta_{h} \frac{1}{U_{h 1}-U_{h 1}\left(x_{h 1}^{0}(p)\right)}-\lambda_{h} & =0 \\
\left(1-\beta_{h}\right) \frac{1}{U_{h 2}-U_{h 2}\left(x_{h 2}^{0}(p)\right)} \frac{\partial V_{h 2}}{\partial x_{h 2}^{k}}-\lambda_{h} p_{k} & =0, \quad k=1, \ldots, \ell-1 \\
\left(1-\beta_{h}\right) \frac{1}{U_{h 2}-U_{h 2}\left(x_{h 2}^{0}(p)\right)}-\lambda_{h} & =0
\end{aligned}
$$

Therefore:

\footnotetext{
${ }^{7}$ Note that our assumption of sufficient endowments of all households with the numéraire good allows us to work with the entire set of first-order conditions.
} 


$$
\begin{gathered}
\lambda_{h}=\beta_{h} \frac{1}{U_{h 1}-U_{h 1}\left(x_{h 1}^{0}(p)\right)}=\left(1-\beta_{h}\right) \frac{1}{U_{h 2}-U_{h 2}\left(x_{h 2}^{0}(p)\right)} \\
\frac{\partial V_{h 1}}{\partial x_{h 1}^{k}}=\frac{\partial V_{h 2}}{\partial x_{h 2}^{k}}=p_{k}, \quad k=1, \ldots, \ell-1
\end{gathered}
$$

Hence, the demand of household $h$ for commodities $k=1, \ldots, \ell-1$ is independent of the bargaining power $\beta_{h}$ and $1-\beta_{h}$ of individual $h 1$ and $h 2$, respectively. Hence, by the budget constraint and budget exhaustion also the aggregate household demand for commodity $\ell$ is independent of $\beta_{h}$. Therefore, market equilibria do not depend on internal bargaining power of households and, hence, changes of bargaining power in household $h$ have no effect on equilibrium prices. This establishes points (i) and (ii). However, a shift of the power in households affects the distribution of the numéraire good in household $h$. Using the notation for the equilibria we have from equation (13):

$$
\frac{\beta_{h}}{\widehat{V}_{h 1}+\widehat{x}_{h 1}^{\ell}+v_{1}-U_{h 1}\left(x_{h 1}^{0}(p)\right)}=\frac{1-\beta_{h}}{\widehat{V}_{h 2}+\widehat{x}_{h 2}^{\ell}+v_{2}-U_{h 2}\left(x_{h 2}^{0}(p)\right)}
$$

Since $\widehat{V}_{h 1}, v_{1}, U_{h 1}\left(x_{h 1}^{0}(p)\right)$ and $\widehat{V}_{h 2}, v_{2}, U_{h 2}\left(x_{h 2}^{0}(p)\right)$ are independent of $\beta_{h}$ and $\widehat{x}_{h 1}^{\ell}+\widehat{x}_{h 2}^{\ell}$ does not depend on $\beta_{h}$ either, we obtain the third point (iii):

$$
\frac{\partial \widehat{x}_{h 1}^{\ell}}{\partial \beta_{h}}>0, \quad \frac{\partial \widehat{x}_{h 2}^{\ell}}{\partial \beta_{h}}<0
$$

If households are completely homogeneous with respect to $U_{h i}$ and $w_{h}$, a household equilibrium does not involve any positive net trades, again using the fact that differences in $\beta_{h}$ have no effect on aggregate excess demand. Therefore, $\widehat{x}_{h 1}^{\ell}+\widehat{x}_{h 2}^{\ell}=\bar{w}_{h}^{\ell}$ and via equation (15) we obtain (iv). 


\section{References}

Apps, P. and R. Rees: "Collective Labor Supply and Household Production", Journal of Political Economy 105 (1997), 178-190.

Apps, P. and R. Rees: "Household Models: An Historical Perspective", CESifo Working Paper No. 2172, 2007.

Becker, G.S.: "Nobel Lecture: The Economic Way of Looking at Behavior", Journal of Political Economy 101 (1993), 385-409.

Bell, C: "Markets, Power and Productivity in Rural Asia: a Review Article", Journal of Development Economics 36 (1991), 373-393.

Chiappori, P.-A.: "Rational Household Labor Supply," Econometrica 56 (1988a), 6389.

Chiappori, P.-A.: "Collective Labor Supply and Welfare," Journal of Political Economy 100 (1992), 437-467.

Ellickson, B.: Competitive Equilibrium. Cambridge University Press: Cambridge, 1993.

Gersbach, H., and H. Haller: "Collective Decisions and Competitive Markets," Review of Economic Studies 68 (2001), 347-368.

Gersbach, H., and H. Haller: "Competitive Markets, Collective Decisions and Group Formation," CESifo Working Paper No. 953, 2003.

Haller, H.: "Household Decisions and Equilibrium Efficiency", International Economic Review 41(4), (2000), 835-847.

Hirschman, A.O.: Exit, Voice, and Loyality, Harvard University Press, Cambridge, Massachusetts, 1970. (1985).

Makowski, L., Ostroy, J. M., and U. Segal: "Efficient Incentive Compatible Economies are Perfectly Competitive," Journal of Economic Theory 85 (1999), 169-225. 


\section{CESifo Working Paper Series}

for full list see www.cesifo-group.org/wp

(address: Poschingerstr. 5, 81679 Munich, Germany, office@cesifo.de)

2305 Tomer Blumkin, Yoram Margalioth and Efraim Sadka, The Role of Stigma in the Design of Welfare Programs, May 2008

2306 Vesa Kanniainen and Paolo M. Panteghini, Tax Neutrality: Illusion or Reality? The Case of Entrepreneurship, May 2008

2307 Thomas Dohmen, Armin Falk, David Huffman and Uwe Sunde, The Intergenerational Transmission of Risk and Trust Attitudes, May 2008

2308 Guglielmo Maria Caporale and Mario Cerrato, Using Chebyshev Polynomials to Approximate Partial Differential Equations, May 2008

2309 Peter Egger and Doina Maria Radulescu, Labour Taxation and Foreign Direct Investment, May 2008

2310 Laurent Linnemer, Dissipative Advertising Signals Quality even without Repeat Purchases, May 2008

2311 Jordi Jofre-Monseny and Albert Solé-Ollé, Which Communities should be afraid of Mobility? The Effects of Agglomeration Economies on the Sensitivity of Firm Location to Local Taxes, May 2008

2312 Andreas Haufler and Ferdinand Mittermaier, Unionisation Triggers Tax Incentives to Attract Foreign Direct Investment, May 2008

2313 Ronel Elul and Piero Gottardi, Bankruptcy: Is it enough to Forgive or must we also Forget?, May 2008

2314 Andreas Irmen and Johanna Kuehnel, Productive Government Expenditure and Economic Growth, May 2008

2315 Beate Henschel, Carsten Pohl and Marcel Thum, Demographic Change and Regional Labour Markets: The Case of Eastern Germany, May 2008

2316 Gabriel Felbermayr, Wido Geis and Wilhelm Kohler, Restrictive Immigration Policy in Germany: Pains and Gains Foregone?, May 2008

2317 Michael Hofmann, Gerhard Kempkes and Helmut Seitz, Demographic Change and Public Sector Budgets in a Federal System, May 2008

2318 Paul De Grauwe, Macroeconomic Modeling when Agents are Imperfectly Informed, June 2008

2319 Johann K. Brunner and Susanne Pech, Optimum Taxation of Inheritances, June 2008 
2320 Thomas Eichner and Marco Runkel, Corporate Income Taxation of Multinationals in a General Equilibrium Model, June 2008

2321 Rainald Borck and Matthias Wrede, Subsidies for Intracity and Intercity Commuting, June 2008

2322 Patricia Apps and Ray Rees, Testing the Pareto Efficiency of Household Resource Allocations, June 2008

2323 Amihai Glazer, Vesa Kanniainen and Panu Poutvaara, Firms' Ethics, Consumer Boycotts, and Signalling, June 2008

2324 Claudia M. Buch, Jörg Döpke and Kerstin Stahn, Great Moderation at the Firm Level? Unconditional vs. Conditional Output Volatility, June 2008

2325 Helmuth Cremer, Philippe De Donder, Dario Maldonado and Pierre Pestieau, Forced Saving, Redistribution and Nonlinear Social Security Schemes, June 2008

2326 M. Hashem Pesaran and Paolo Zaffaroni, Optimal Asset Allocation with Factor Models for Large Portfolios, June 2008

2327 Harald Badinger and Peter Egger, Horizontal versus Vertical Interdependence in Multinational Activity, June 2008

2328 Jan K. Brueckner and Harris Selod, A Theory of Urban Squatting and Land-Tenure Formalization in Developing Countries, June 2008

2329 Paolo M. Panteghini, Corporate Debt, Hybrid Securities and the Effective Tax Rate, June 2008

2330 Guglielmo Maria Caporale, Juncal Cuñado and Luis A. Gil-Alana, Modelling Long-Run Trends and Cycles in Financial Time Series Data, June 2008

2331 Avi Ben-Bassat and Momi Dahan, Social Identity and Voter Turnout, June 2008

2332 Martin R. West and Ludger Wößmann, "Every Catholic Child in a Catholic School”: Historical Resistance to State Schooling, Contemporary Private Competition, and Student Achievement across Countries, June 2008

2333 Erkki Koskela and Panu Poutvaara, Outsourcing and Labor Taxation in Dual Labor Markets, June 2008

2334 Philippe Choné and Laurent Linnemer, Optimal Litigation Strategies with Signaling and Screening, June 2008

2335 Albert Solé-Ollé and Pilar Sorribas-Navarro, Does Partisan Alignment Affect the Electoral Reward of Intergovernmental Transfers?, June 2008

2336 Antonio Cabrales and Piero Gottardi, Markets for Information: Of Inefficient Firewalls and Efficient Monopolies, June 2008 
2337 Sumon Majumdar and Sharun W. Mukand, The Leader as Catalyst - on Leadership and the Mechanics of Institutional Change, June 2008

2338 Ulrich Hange, Tax Competition, Elastic Labor Supply, and Growth, June 2008

2339 Guy Laroque and Bernard Salanié, Does Fertility Respond to Financial Incentives?, June 2008

2340 Adriano Paggiaro, Enrico Rettore and Ugo Trivellato, The Effect of Extending the Duration of Eligibility in an Italian Labour Market Programme for Dismissed Workers, June 2008

2341 Helmut Seitz, Minimum Standards, Fixed Costs and Taxing Autonomy of Subnational Governments, June 2008

2342 Robert S. Chirinko, Leo de Haan and Elmer Sterken, Asset Price Shocks, Real Expenditures, and Financial Structure: A Multi-Country Analysis, July 2008

2343 Wolfgang Leininger, Evolutionarily Stable Preferences in Contests, July 2008

2344 Hartmut Egger and Udo Kreickemeier, Fairness, Trade, and Inequality, July 2008

2345 Ngo Van Long and Bodhisattva Sengupta, Yardstick Competition, Corruption, and Electoral Incentives, July 2008

2346 Florian Baumann, Employment Protection: The Case of Limited Enforceability, July 2008

2347 Alessandro Balestrino, Cinzia Ciardi and Claudio Mammini, On the Causes and Consequences of Divorce, July 2008

2348 Dirk Schindler and Benjamin Weigert, Insuring Educational Risk: Opportunities versus Income, July 2008

2349 Lammertjan Dam and Ben J. Heijdra, The Environmental and Macroeconomic Effects of Socially Responsible Investment, July 2008

2350 Avner Greif, Contract Enforcement and Institutions among the Maghribi Traders: Refuting Edwards and Ogilvie, July 2008

2351 Helmuth Cremer, Philippe De Donder, Dario Maldonado and Pierre Pestieau, Habit Formation and Labor Supply, July 2008

2352 Francesco Menoncin and Paolo M. Panteghini, The Johansson-Samuelson Theorem in General Equilibrium: A Rebuttal, July 2008

2353 Michael Kaganovich and Itzhak Zilcha, Alternative Social Security Systems and Growth, July 2008 
2354 Keith Blackburn, Kyriakos C. Neanidis and M. Emranul Haque, Corruption, Seigniorage and Growth: Theory and Evidence, July 2008

2355 Edward Castronova, A Test of the Law of Demand in a Virtual World: Exploring the Petri Dish Approach to Social Science, July 2008

2356 Harald Badinger and Peter Egger, GM Estimation of Higher-Order Spatial Autoregressive Processes in Cross-Section Models with Heteroskedastic Disturbances, July 2008

2357 Wolfgang Buchholz and Jan Schumacher, Discounting the Long-Distant Future: A Simple Explanation for the Weitzman-Gollier-Puzzle, July 2008

2358 Luca Anderlini, Leonardo Felli and Alessandro Riboni, Statute Law or Case Law?, July 2008

2359 Guglielmo Maria Caporale, Davide Ciferri and Alessandro Girardi, Are the Baltic Countries Ready to Adopt the Euro? A Generalised Purchasing Power Parity Approach, July 2008

2360 Erkki Koskela and Ronnie Schöb, Outsourcing of Unionized Firms and the Impacts of Labour Market Policy Reforms, July 2008

2361 Francisco Alvarez-Cuadrado and Ngo Van Long, A Permanent Income Version of the Relative Income Hypothesis, July 2008

2362 Gabrielle Demange, Robert Fenge and Silke Uebelmesser, Financing Higher Education and Labor Mobility, July 2008

2363 Alessandra Casarico and Alessandro Sommacal, Labor Income Taxation, Human Capital and Growth: The Role of Child Care, August 2008

2364 Antonis Adam, Manthos D. Delis and Pantelis Kammas, Fiscal Decentralization and Public Sector Efficiency: Evidence from OECD Countries, August 2008

2365 Stefan Voigt, The (Economic) Effects of Lay Participation in Courts - A Cross-Country Analysis, August 2008

2366 Tobias König and Andreas Wagener, (Post-)Materialist Attitudes and the Mix of Capital and Labour Taxation, August 2008

2367 Ximing Wu, Andreas Savvides and Thanasis Stengos, The Global Joint Distribution of Income and Health, August 2008

2368 Alejandro Donado and Klaus Wälde, Trade Unions Go Global!, August 2008

2369 Hans Gersbach and Hans Haller, Exit and Power in General Equilibrium, August 2008 